\title{
Retracted: Circularly Polarized Wideband Fabric Stealth Multiple-Input Multiple-Output Antenna for Ultrawideband Applications Useful for Wireless Systems Wearable on Garments
}

\author{
International Journal of Antennas and Propagation
}

Received 28 June 2022; Accepted 28 June 2022; Published 19 August 2022

Copyright $\odot 2022$ International Journal of Antennas and Propagation. This is an open access article distributed under the Creative Commons Attribution License, which permits unrestricted use, distribution, and reproduction in any medium, provided the original work is properly cited.

International Journal of Antennas and Propagation has retracted the article titled "Circularly Polarized Wideband Fabric Stealth Multiple-Input Multiple-Output Antenna for Ultrawideband Applications Useful for Wireless Systems Wearable on Garments" [1], due to significant overlap identified with a previous publication [2].

Author Pillalamarri Laxman agrees to the retraction and the notice. Author Anuj Jain has not responded to correspondence from the publisher regarding this retraction.

\section{References}

[1] P. Laxman and A. Jain, "Circularly Polarized Wideband Fabric Stealth Multiple-Input Multiple-Output Antenna for Ultrawideband Applications Useful for Wireless Systems Wearable on Garments," International Journal of Antennas and Propagation, 2021.

[2] S. Kumar, D. Nandan, K. Srivastava et al., "Wideband Circularly Polarized Textile MIMO Antenna for Wearable Applications," IEEE Access, vol. 9, pp. 108601-108613, 2021. 


\title{
Circularly Polarized Wideband Fabric Stealth Multiple-Input Multiple-Output Antenna for Ultrawideband Applications Useful for Wireless Systems Wearable on Garments
}

\author{
Pillalamarri Laxman (iD) and Anuj Jain \\ School of Electronics and Electrical Engineering, LP University, Punjab, India
}

Correspondence should be addressed to Pillalamarri Laxman; laxmanpillalamarri@gmail.com

Received 20 August 2021; Revised 18 October 2021; Accepted 30 October 2021; Published 18 November 2021

Academic Editor: Renato Cicchetti

Copyright ( 2021 Pillalamarri Laxman and Anuj Jain. This is an open access article distributed under the Creative Commons Attribution License, which permits unrestricted use, distribution, and reproduction in any medium, provided the original work is properly cited.

\begin{abstract}
Stealth wearable wireless devices are gaining much attention in the personal security and fashion designing industry. A multipleinput multiple-output wideband circularly polarized antenna wearable on a dress (textile-related), which is immune to bending, is described in this paper, where a wearable on fabric dress application uses the MIMO techniques. It consists of two multiple-input multiple-output types of antenna elements: the resonating elements are created resembling a beautiful peacock shape and the ground plane is appropriately designed. A voltage is applied to each antenna element; the ground plane contains a microstrip transmission line-fed and a rectangular upside-down L-shaped (vertically flipped) strip used for circular polarizing. The antenna covers a $3 \mathrm{~dB}$ axial-ratio-band-width (ARBW) value of $5.20-7.10 \mathrm{GHz}$ and impedance bandwidth (S11 less than $-10 \mathrm{~dB}$ ) of 03.60-13.0 GHz. The proposed attachable wearable fabric (textile) multiple-input multiple-output wideband antenna exhibits envelope correlation coefficient (ECC) $<0.02$, diversity gain $(\mathrm{DG})>9.96$, channel capacity loss $(\mathrm{CCL})<0.2 \mathrm{~b} / \mathrm{s} / \mathrm{Hz}$, total active reflective coefficient (TARC) $<-10 \mathrm{~dB}$, mean effective gain $(\mathrm{MEG})$ ratio within $\pm 0.5 \mathrm{~dB}$. There is dual-sense circular polarization in this antenna and high isolation between resonating elements (higher than 18). A specific absorption rate (SAR) of the proposed antenna for human tissues specimen is also discussed for different situations related to the human body. The overall size of the proposed CP textile MIMO antenna is $34: 5 \times 42 \times 1 \mathrm{~mm}^{3}$. Because of its clothing layers (textile), practical performance, and miniature size, the designed MIMO antenna may be helpful for wearable on cloths on human body wireless devices and systems. The proposed antenna can be made unrecognizable because of the beautiful peacock design that can easily mix with the designs of fabric (in the fashion dress). The simulated antenna was fabricated with the help of conventional manual fabrication techniques and tested in real-time situations. The edge-to-edge distance amid the MIMO radiating antennas is $14.2 \mathrm{~mm}$, and the achieved isolation is greater than $18 \mathrm{~dB}$ after optimization of the proposed antenna.
\end{abstract}

\section{Introduction}

Designers are paying considerable attention to wearable gadgets because of their numerous uses in hospital care, hobbies, map-reading, monitoring, and safety $[1,2]$. The antenna element is a vital component of wearable on garment transceiver systems. To radiate efficiently through bending, running, running, and movements, wearable/textile antennas are required. Antennas on textiles must be easy to integrate into minisized electronic gadgets or garments because they should be minisize, conformal, negligible in weight, bendable, tough, and miniature-sized [3]. A wearable antenna is designed for near staying to the human being's body. Fabrication, antenna placement, and structural deformation are all factors to consider when designing textile antennas $[4,5]$. In addition to their orientation suppleness, mobility, and invulnerability to multipath interference, wearable applications requiring wideband circularly polarized (CP) antennas are becoming increasingly attractive [6-8]. A growing number of companies are focusing on multiple-input multiple-output (MIMO) and diversity technologies to improve link capacity, especially in 
multifaceted multipath environments. For establishing reliable channels and dealing with multipath fading, multielement antennas with polarization diversity are the best choice [9-11].

An MIMO system can serve a wide range of applications with several special advantages such as beam-steering, increased data capacity, multiplexing, and greater diversity. A single antenna system cannot improve the communication system's capacity as effectively as a multiantenna MIMO system. MIMO has uniformly distributed energy across the structure, increased capacity coverage, increased transmission range for a fixed data rate, increased spectral efficiency (bits per sec per $\mathrm{Hz}$ of the channel), substantially boosted speed, and link robustness in multipath environments. There have been many wearable MIMO antenna elements with larger interelement isolation introduced in literature $[12,13]$. Using vias to modify the resonant mode of the waveguide cavity, [13] developed a wearable on cloths-based dual-band multiple-input multiple-output type of antenna for wireless LAN applications. A radiation antenna element with a circular shape and a high impedance surface (HIS) has been described [14], which provided isolation between the ports of more than $15 \mathrm{~dB}$. Wearable applications were demonstrated using a textile MIMO antenna embedded in a single-coat fabric [15]. Here, the ground plane served as the radiating element. Double-element wearable on cloths (garments) MIMO antennas were presented for ultrawideband (UWB) wireless systems, which were isolated by at least $26 \mathrm{~dB}$ using a partially suppressed ground plane in [16]. An I-shaped stub was used to achieve larger interradiator element isolation on a rectangular-fashioned textile wearable MIMO antenna element described clearly in [17]. An inverted-L planar strip ground plane was used in [12] to achieve wide axial ratio bandwidth (ARBW) by feeding a coplanar waveguide (CPW) into a square slot MIMO antenna. A few technologies that can be utilized for WLAN, C-band, and satellite applications have been developed in the last five years from [12, 18-21]. It was reported in [18] that a dual $\mathrm{CP}$ antenna could be formed by combining L-shaped strips in order to obtain circular polarization. The ground plane of [19] was proposed with a mirrored F-shaped defected ground structure (DGS) combined with a CP MIMO antenna composed of grounded stubs. It is shown in [20] that the orthogonal field induction is achieved through the modification to the ground plane of the CP antenna. According to [21], a CP MIMO antenna for wearable gadgets can navigate phase differences between orthogonal modes using an implement implanted in the ground plane. In [13-17], MIMO antennas showed linear polarization (LP) characteristics, while from [12] through [21], CP characteristics were presented. There have been very few reports on wearable/textile antennas that have a wide ARBW. An alternative to the dish-shaped reflector is proposed in paper [22] in the form of a low-profile planar antenna. A near-field phase transforming metasurface is mounted on an array of resonant cavity antennas (RCAs). Using this antenna, the beam is pointed at an elevation angle of 20 degrees with a peak directivity of $22 \mathrm{dBi}$. In the literature, a planar and low-profile antenna system as an alternative to the dish-shaped reflector for receiving DBS services around the world is made of an array of cavity antennas (RCAs) which has achieved $22 \mathrm{dBi}$ peak directivity and a 20-degree elevation angle beam at $11 \mathrm{GHz}$. An antenna array comprised of conjoined twin "Y-shape" microstrip structures [23], operating in the terahertz $(\mathrm{THz})$ band of 139-141 GHz for applications such as a transceiver, medical, and security-related systems, is described in this paper using a novel $2 \mathrm{D}$ metasurface wall to increase the isolation between microstrip patch radiators. Over $10 \mathrm{~dB}$ of mutual coupling suppression is achieved using the proposed technique over a broader frequency band $(2 \mathrm{GHz})$ than has been achieved before. A decoupling structure [24] based on fractal MTM-EMBG was presented to improve isolation in antenna arrays using a fractal isolator which has a negligible effect on the antenna array's frequency bandwidth and radiation gain and achieved over $17 \mathrm{~dB}$ isolation and an edge-to-edge separation between antennas is $0.5 \lambda$ especially useful to closely packed patch antenna arrays for MIMO systems. A low-profile dense antenna [25] array with improved isolation (by $26.7 \mathrm{~dB}$ in X-band and $>15 \mathrm{~dB}$ in $\mathrm{Ku}$ and $\mathrm{K}$-bands) between neighboring antennas and improved gain by $>40 \%$ within a narrower angular direction is introduced. It introduced a technique to reduce mutual coupling between adjacent antennas, permitting the reduced edge-to-edge gap of $10 \mathrm{~mm}(0.37 \lambda)$, which is capable of larger angle MIMO beam scanning. Paper [26] disclosed a coupling reduction method without using via or double-sided etching provided $23 \mathrm{~dB}$ reduction and increased gain by using 2 array antennas with a spacing of $0 \lambda$ and $0 / 3 \lambda$. Another excellent versatile technique [27] to enhance the isolation between antennas is especially useful for densely packed MIMO arrays by using metamaterial decoupling slab (MTM-DS). This has an isolation improvement of $-38 \mathrm{~dB}, 15 \%$ improvement in bandwidth eliminating poor front-to-back ratio, and isolation (s12) of $-27 \mathrm{~dB}$ for frequency beam scanning in MIMO and SARs. Reference [28] presented an excellent combination of MS (multisigma) and MT (multitau) and meander line techniques for bandwidth improvement (86\%), size reduction, improved peak gain $(3.7 \mathrm{~dB})$, and radiation efficiency (90\%). The survey article [29] discussed plenty of decoupling mechanisms focusing on applicable to SAR and MIMO antenna arrays and also [30, 31].

An article on miniature profile, wearable, portable-sized, double-element circularly polarized multiple-input-multiple-output antenna and wearable on (garments) textile mountable antennas for movable mobile wireless system applications is presented here. It comprises a peacockshaped microstrip transmission line-fed antenna element and modified ground plane. Using an L-shaped stub, a quadrature phase shift introduced electric field vectors amid the vertical and horizontal. Dual-sensor radiation characteristics are achieved by locating the two antenna elements in a mirrored-image configuration. CP (left-hand CP) waves are emitted by port 1 , while $\mathrm{CP}$ waves (right-hand $\mathrm{CP}$ ) are emitted by port 2. Due to this property, the presented MIMO antenna is appropriate for polarization diversity. 


\section{Configuration of Proposed Stealth Antenna}

2.1. Antenna Element Design. The proposed CP fabric antenna element is shown in Figure 1. The author tried to identify a beautiful and more appealing design that is suitable for designer-made dresses and should be unnoticeable to the public. The proposed design targets stealth mode invisible (secrete) wearable communication devices. Antenna element dimensions are $20 \mathrm{~mm} \times 30: 5 \mathrm{~mm}$. On the upper and lower sides of the dielectric substrate, the antenna element contains a peacock-shaped radiating antenna microstrip patch and a modified ground plane, shown in Figures 1(b) and 1(c). The antenna element consists of a $1 \mathrm{~mm}$ thick felt substrate material, with a 1.34 dielectric constant and a loss tangent of 0.02. A shielded superconductive material of thickness $0.17 \mathrm{~mm}$ and a surface resistance of $0.5 \mathrm{ohms}$ per one square is employed to produce the radiating microstrip patch and the ground plane. An HFSS R simulation is performed using ANSYS HFSS $R$ software to simulate the proposed antenna. The radiator is supplied by way of a fifty-ohm microstrip patch transmission line.

The design parameters of the antenna element are $R 1 \mathrm{D}$ $11: 5 \mathrm{~mm}, R 2 \mathrm{D} 10: 3 \mathrm{~mm}, R 3 \mathrm{D} 13: 8 \mathrm{~mm}$, Lf D $10: 20 \mathrm{~mm}$, $L 1 \mathrm{D} 23: 40 \mathrm{~mm}, W 1 \mathrm{D} 1: 70 \mathrm{~mm}, L 2 \mathrm{D} 10: 5 \mathrm{~mm}, W 2 \mathrm{D}$ $3.0 \mathrm{~mm}, L 3 \mathrm{D} 5: 70 \mathrm{~mm}, W 3 \mathrm{D} 5 \mathrm{~mm}, L 4 \mathrm{D} 7: 7 \mathrm{~mm}$, and $W 4$ D $20 \mathrm{~mm}$.

As can be seen from Figure 2, the proposed antenna evolves from left to right. In the diagram, on the right (d), we see the final antenna for simulation and fabrication. A final antenna in Figure 2(d) looks almost similar to a peacock, which is aesthetically pleasing and can be incorporated into wearable fancy dresses. This antenna is primarily intended for use in fancy dresses, and special care is focused on the unrecognizable nature. A piece like this antenna can be incorporated into jewelry, embroidery, or similar artwork on wearable garments.

2.1.1. Design Process. The evolution process of the textile antenna element is shown in Figure 2. Figures 3(a) and 3(b) show the computer (simulated)-generated reflection coefficients and axial ratio curves from the design phases, respectively. The top of Figure 2(a) shows a microstrip linefeed peacock-shaped antenna element, and the bottom shows a partially grounded ground plane. Antenna 1 exhibits resonating bandwidths of $3.6-4.5 \mathrm{GHz}$ and $7.5-11.3 \mathrm{GHz}$. Step 2, as depicted in Figure 2(b), adds a strip of wavelength lambda/2 to the partial ground plane to pick up impedance bandwidth. Two resonating bands are also visible in antenna 2.

An L-fashioned microstrip inserted in the ground plane (antenna 3) overcomes the mismatch in impedance, as shown in Figure 2(c). Besides the L-shaped strip, the voltage induced by the two electric field vectors (Ex and Ey) is also in quadrature phase difference. $5.5-10.4 \mathrm{GHz}$ and $5.3-5.8 \mathrm{GHz}$ are the impedance and axial ratio bandwidths (ARBWs) of the antenna 3. By alienating the L-shaped strip into two parts (of $\mathrm{L} 2 * \mathrm{~W} 2$ and $\mathrm{L} 1 * \mathrm{~W} 1$ ), revealed in Figure $2(\mathrm{~d}$ ), one can improve the axial ratio of the antenna (antenna 4 ) in step 4.
To cover the lower frequency range, the antenna resonating band needs to shift to the left side. The antenna element therefore has a rectangular slot (with dimensions L3 $* \mathrm{~W} 3$ ) etched from its ground plane, as can be seen in Figure 2(e). Therefore, the current operating frequency band changes to the lower side when the path length increases. In addition, the proposed antenna 5 achieves superior CP performance. In Table 1, you will find the simulation results (impedance bandwidth and ARBW) of every stage.

2.1.2. Circular Polarization (CP) Performance. Antenna stages are illustrated in Figure 3(b), indicating axial ratios and frequencies. Antenna 1 vector in stage 1 is LP as the vector phase contrast amid the electric field vectors is not 90 degrees. Likewise, antenna 2 is also LP.

Furthermore, a rectangular ground plane (antenna 3 and antenna 4) is joined to a series of L-shaped strips of dissimilar widths and lengths in order to obtain a phase difference of 90 degrees amid the electric field vectors. Ex and Ey amplitudes become almost equal when they are separated by $90 *$ phase deviation [12].

An illustration of the surface current distributions for the anticipated wearable antenna element (at $\mathrm{wt}=0 *$, $\mathrm{wt}=90 *$, wt $=180 *$, and $\mathrm{wt}=270 *$ ) is revealed in Figure 4. The orthogonal current vectors $\mathrm{A} 1$ and $\mathrm{A} 2$ are symbolized by $\mathrm{A} 1$, and their sum is represented by $\mathrm{A} 2$. Figure 4 (a) shows that, at wt $=0 *$, the surface current density on the upper part of the patch (A1) and the edge of the L-shaped strip (A2) increase. The sum (A3) of these two vectors is heading upward. Figure $4(\mathrm{~b})$ illustrates that, at $\mathrm{wt}=90 *$, vector sum A3 shifts downward to the lower right, which indicates that the vectors are rotating clockwise over time. The sum (A3) also proceeds clockwise in Figures 4(c) and $4(\mathrm{~d})$ at $\mathrm{wt}=180 *$ and $270 *$, respectively. As a result, the proposed textile antenna can operate in a broadside direction. In Figures 5(a) and 5(b), we show the $|j E x / E y j|$ and phase difference plots of antenna 5 and antenna 1 . By introducing a $90 *$ phase difference between the horizontal and vertical electric field vectors, the L-shaped strip on the ground plane balances the magnitude of both. Current is increased by etching a rectangular slot from the ground plane, thus shifting towards the left side of the resonating frequency band.

2.1.3. Mimo Antenna. Figure 6 shows an antenna configuration with mirrored antenna elements (antenna 5). Microstrip lines of $50 \mathrm{ohms}$ are used to excite the monopole radiators.

Mirrored L-shaped strips are positioned on the back of the textile substrate to form a shared ground plane. The anticipated circularly polarized MIMO antenna element parameters are $\mathrm{Lm}=34.50 \mathrm{~mm}, W \mathrm{~m}=42.0 \mathrm{~mm}, \mathrm{Lg}=7.20 \mathrm{~mm}$, $1 \mathrm{~s}=16.5 \mathrm{~mm}$, ws $=1 \mathrm{~mm}, l 5=27.8 \mathrm{~mm}, w 5=1.2 \mathrm{~mm}, l 6=$ $9.5 \mathrm{~mm}, \quad w 6=6 \mathrm{~mm}, \quad l 7=5.7 \mathrm{~mm}, \quad w 7=5 \mathrm{~mm}, \quad w 12=$ $1.7 \mathrm{~mm}$, and $d 1=14.2 \mathrm{~mm}$. The proposed textile MIMO antenna measures $42 \times 34.5 \mathrm{~mm}^{2}$. In Figures 6(c) and 6(d), we show the bottom and top views of the textile MIMO antenna sample. 


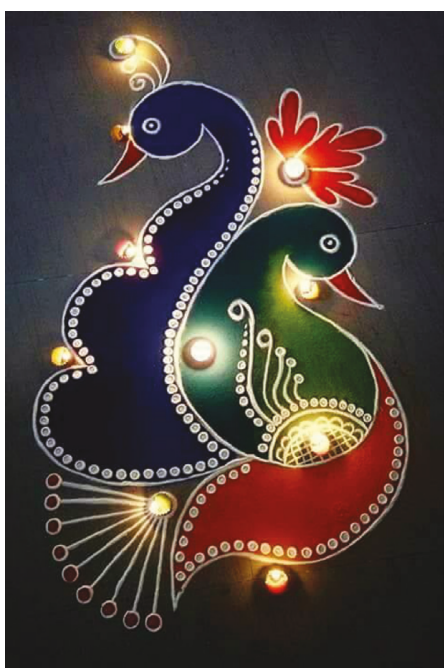

(a)

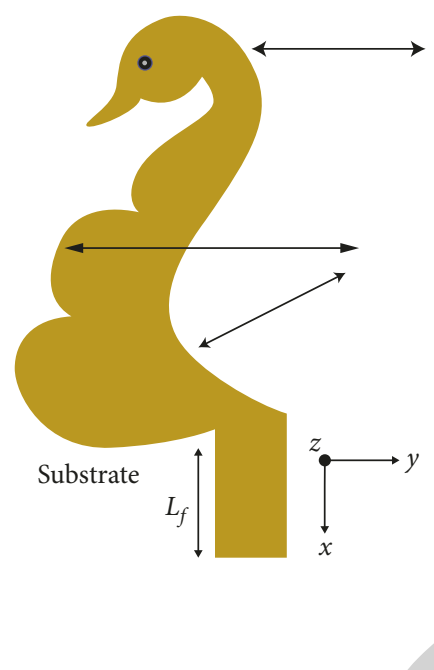

(b)

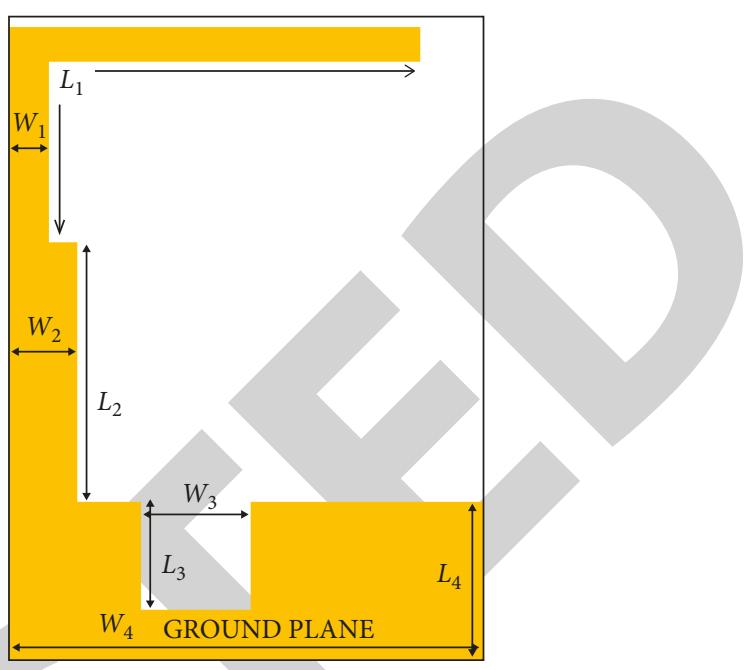

(c)

Figure 1: Proposed stealth CP textile antenna. (a) Stealth fabric design in color. (b) Top view. (c) Bottom view (left to right fig counting).

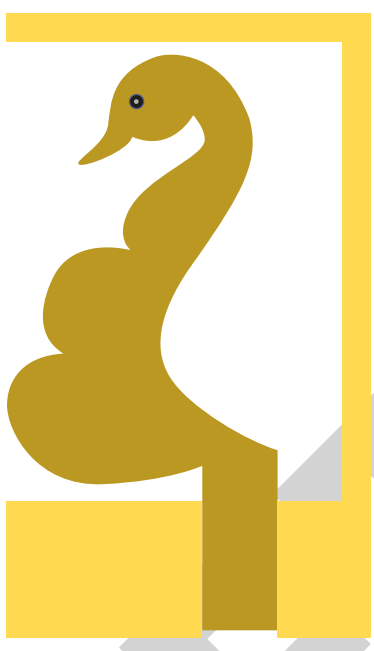

(a)

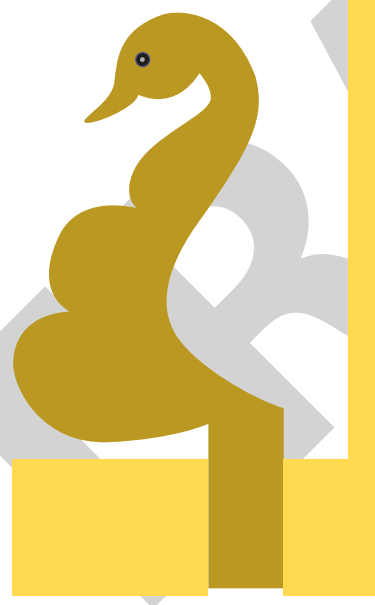

(b)

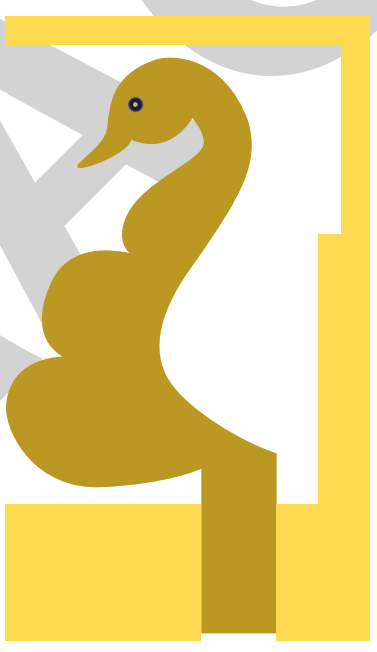

(c)

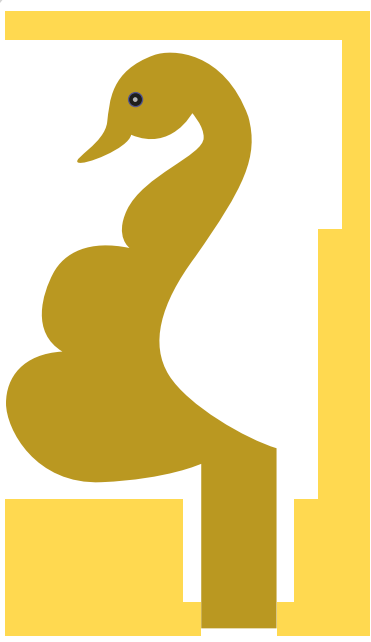

(d)

Figure 2: Evolution of the proposed stealth textile antenna. (a) Antenna 1. (b) Antenna 2. (c) Antenna 3. (d) Antenna 4 (left to right fig counting).

By following traditional methods such as photolithographic techniques and chemical etching processes, the proposed antenna was fabricated as illustrated in [32]. The specified materials were used with accurate precision. The design process involved the selection of the FR4 substrate with copper cladding with the desired thickness. The pattern of the proposed antenna is embossed onto the copper surface of the FR4 plate to etch and remove unwanted copper atoms.

2.1.4. Design Process. Figure 7(a) shows how the MIMO antenna A's L-shaped strips are mirrored-imaged into a T-shaped body near the middle caused by the mirrored-image pattern. The presented MIMO antenna's S12 parameters are stable without any decoupling. As long as there are no decoupling elements between the antenna elements, the present MIMO antenna has stable S12 parameters. Figures 8(a) and 8(b) show the S-parameters and axial ratio curves for the MIMO antennas. Antenna elements are separated by a T-shaped stub that offers superior isolation of more than $16 \mathrm{~dB}$.

In spite of this, the antenna's ACBW varies drastically due to surface wave coupling. The MIMO antenna $\mathrm{A}$ is therefore etched with a rectangular slot (size ls $*$ wsmm 2 ) to improve its $3 \mathrm{~dB}$ ARBW as presented in Figure 7(b) (multiple-input multiple-output antenna B). In addition to improving isolation $(>18.5 \mathrm{~dB})$, the slot would improve MIMO antenna performance. ARBW is realized by optimizing the dimensions of the rectangular slot. Antenna B's simulated impedance bandwidth and ARBW are shown in Table 2.

As illustrated in Figure 8(c), the presented MIMO antenna element is shown in the flat and oblique directions ( $\mathrm{phi}=0$ and 90 degrees), with the beam width simulated at 


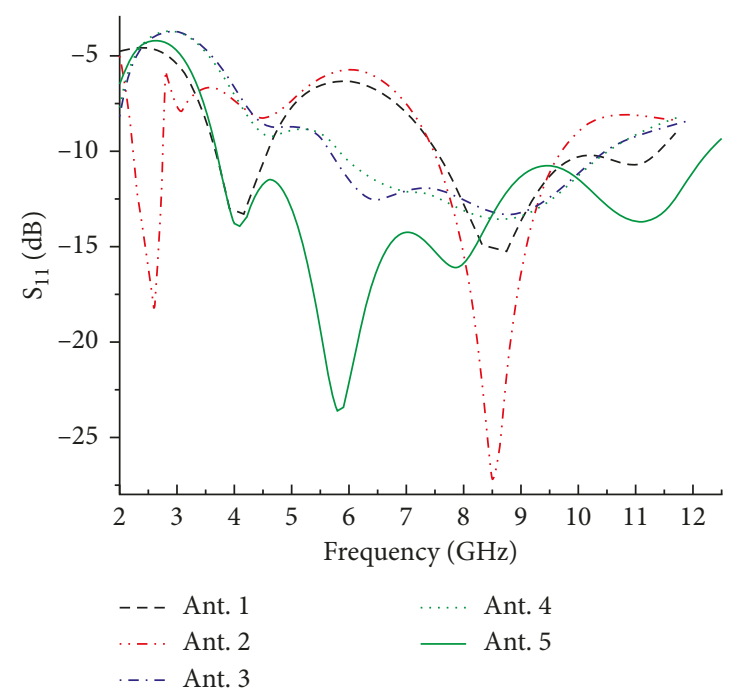

(a)

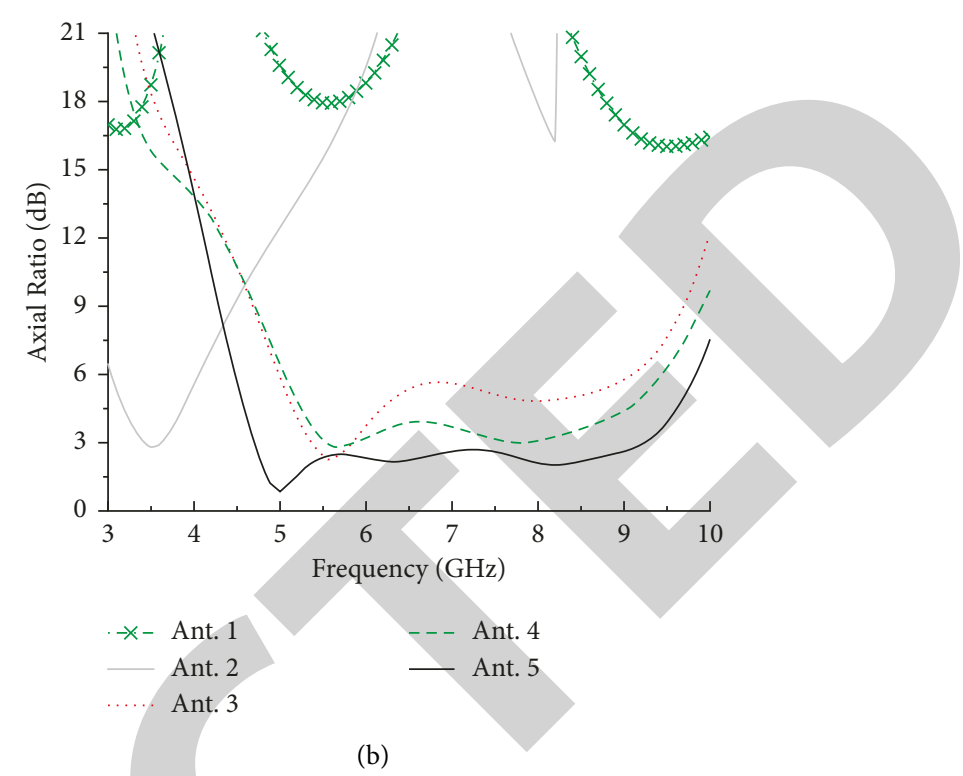

(b)

Figure 3: Computer-generated results of the design steps. (a) Reflection coefficients and (b) axial ratio.

TABLE 1: Correlation of simulated results of the design stages.

\begin{tabular}{lccr}
\hline Step & BW $(\mathrm{GHz})$ & Fractional BW $(\%)$ & ARBW $(\mathrm{GHz})$ \\
\hline Antenna 1 & $3.6-4.5,7.5-11.3$ & $22.22,25.24$ & - \\
Antenna 2 & $2.21-2.87,7.4-9.6$ & $16.6,16.54$ & - \\
Antenna 3 & $5.5-10.4$ & 64.15 & $5.3-5.8$ \\
Antenna 5 (proposed) & $3.7-12.2$ & 106.95 & $4.7-9.21$ \\
\hline
\end{tabular}

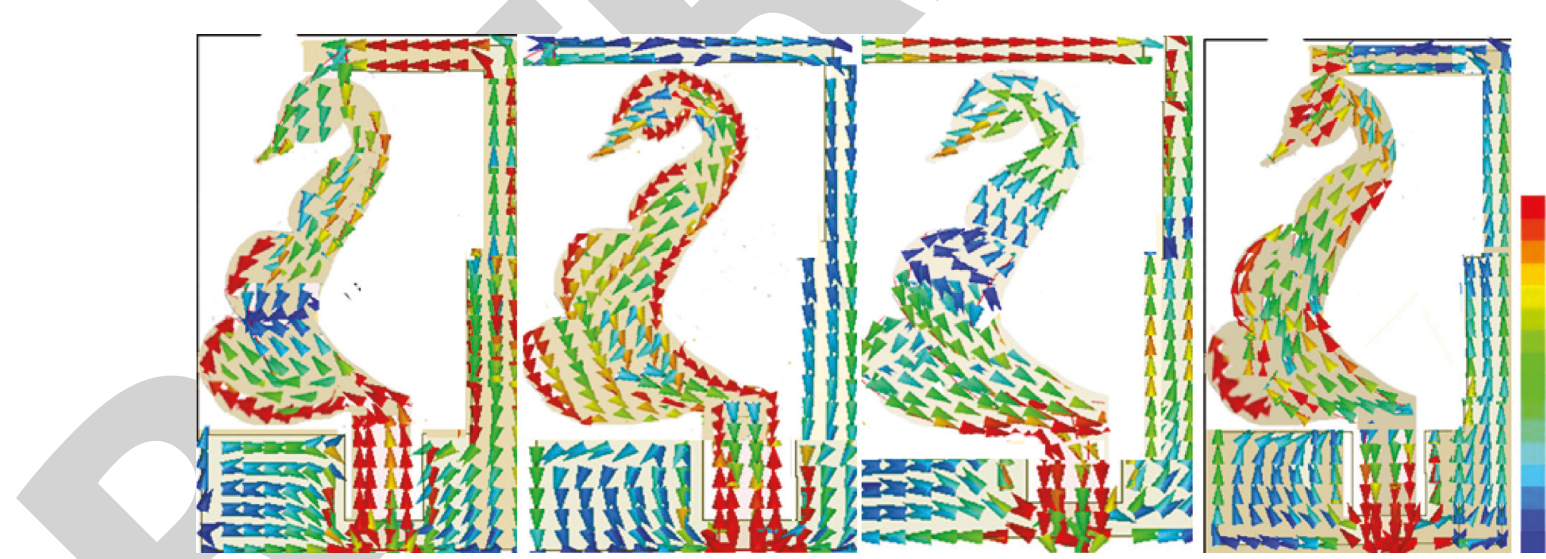

Figure 4: Vector current distribution at $5.25 \mathrm{GHz}$. (a) $0^{\circ}$, (b) $90^{\circ}$, (c) $180^{\circ}$, and (d) $270^{\circ}$. (e) Red indicates the highest peak power, and blue indicates the lowest peak radiation with arrow direction showing flow direction (left to right fig counting).

$6 \mathrm{GHz}$. The observed $3 \mathrm{~dB}$ axial ratio beam widths range from $-68^{\circ}$ to $-62^{\circ}$ for $\varphi=90^{\circ}$ and from $-63^{\circ}$ to $72^{\circ}$ for $\varphi=0^{\circ}$. Figure $8(\mathrm{~d})$ shows both simulated and measured efficiency for the proposed antenna, with the highest efficiency at 9.5 GHz. Because of the dielectric loss, lesser surface area, and portable minisize of the radiating antenna element, the efficiency is low.

2.1.5. Dual-Sense CP Performance. A wearable on garment textile MIMO antenna with double-sense radiation capabilities for two ports has been proposed. A diagram of the surface current distribution of the wearable antenna is illustrated in Figure 9 (at wt $=0$ degrees, wt $=90$ degrees, $w t=180$ degrees, and $w t=270$ degrees). Two orthogonal vectors of current are represented by $\mathrm{A} 1$ and $\mathrm{A} 2$, while their sum is represented by A3.

Either LHCP or RHCP performance can be produced in the broadside direction of the radiating antenna element by adjusting the port excitation. In Figures 9(a) and 9(b), the electric field vectors are illustrated moving clockwise and anticlockwise, respectively. 


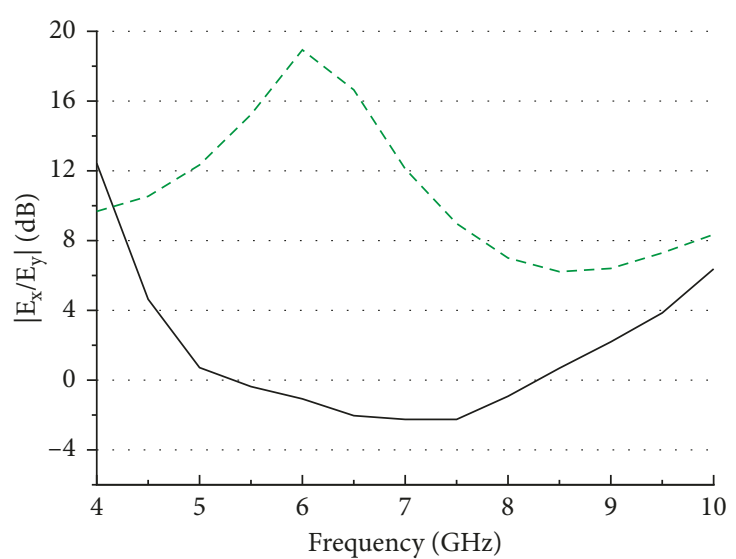

- Antenna 5

- - - Antenna 1

(a)

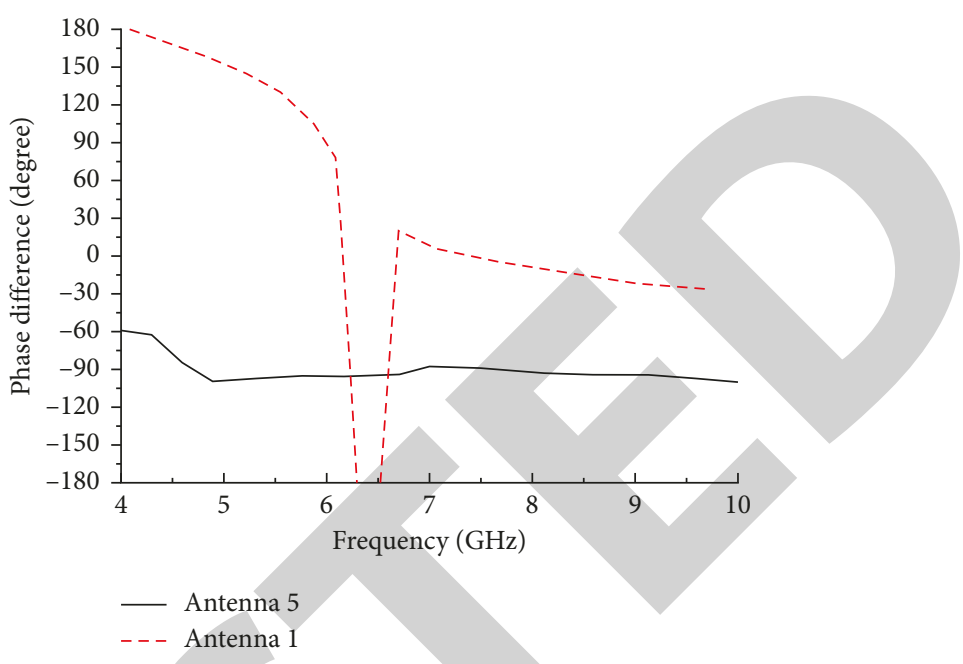

(b)

Figure 5: Comparison between antenna 1 and antenna 5. (a) $\mathrm{j} E x=E y \mathrm{j}$. (b) Phase difference (left to right fig counting).

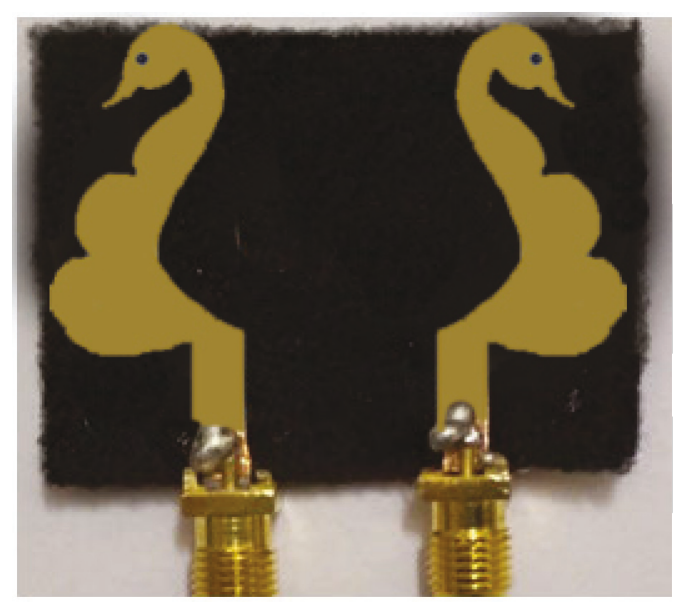

(a)

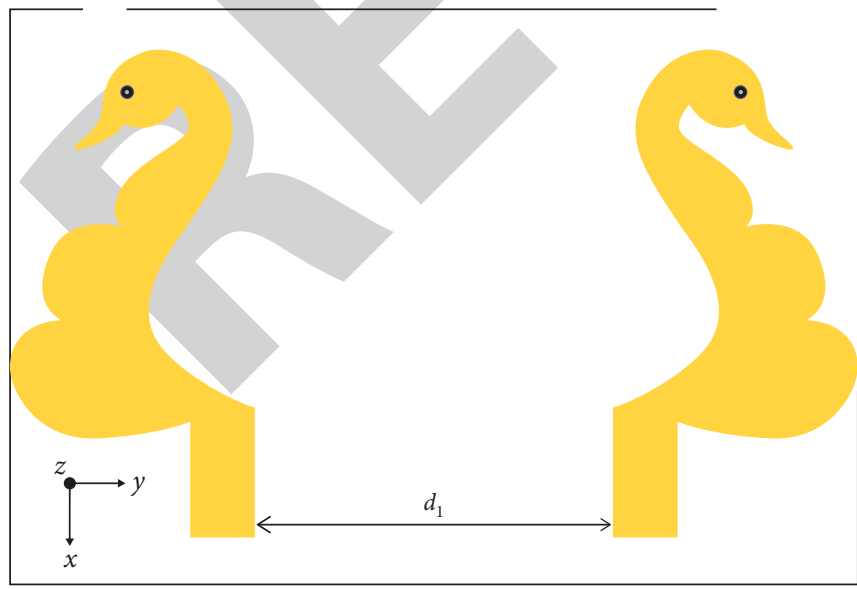

(c)

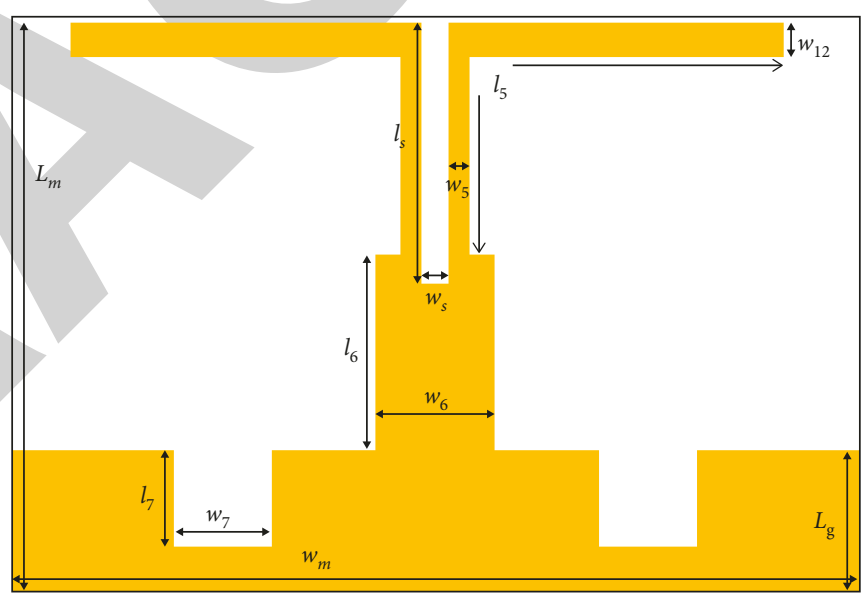

(b)

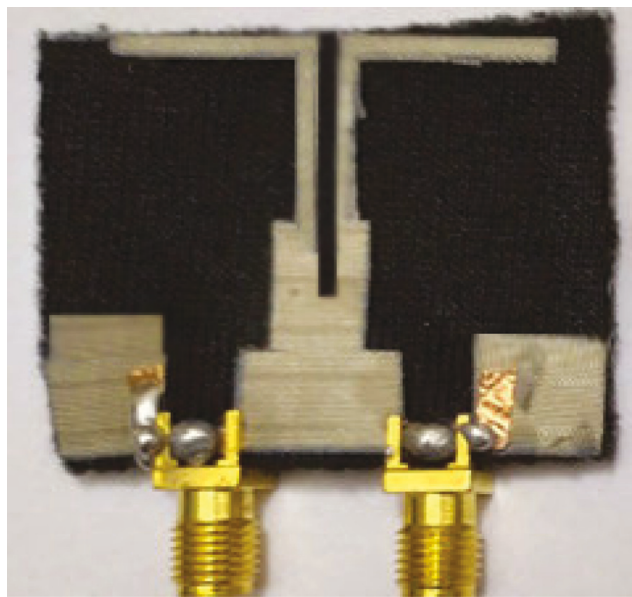

(d)

Figure 6: Proposed Stealth CP textile MIMO antenna. (a) Top view, (b) back view, (c) top view of the fabricated prototype, and (d) bottom view of the fabricated prototype (left to right fig counting). 


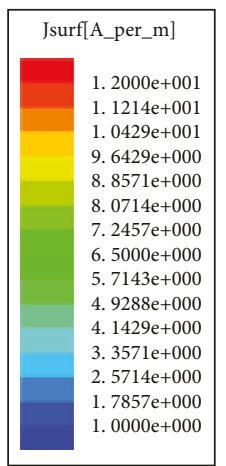

(a)

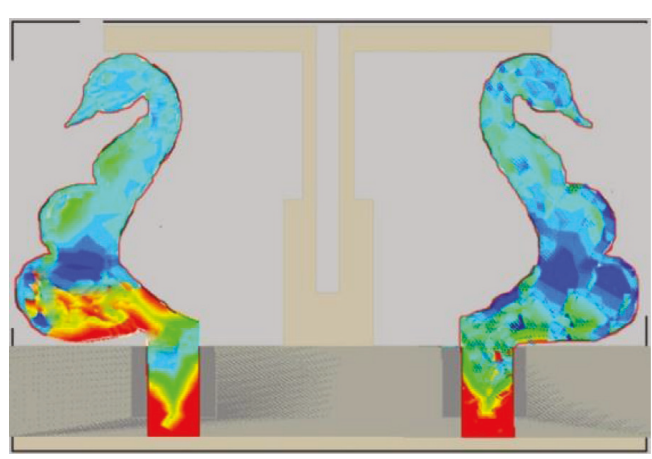

(b)

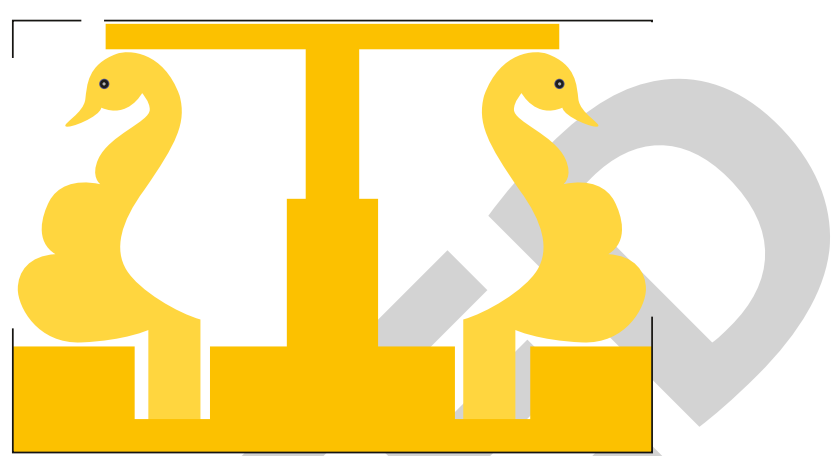

(c)

Figure 7: Design of (a) MIMO antenna A and (b) MIMO antenna B (left to right fig counting).

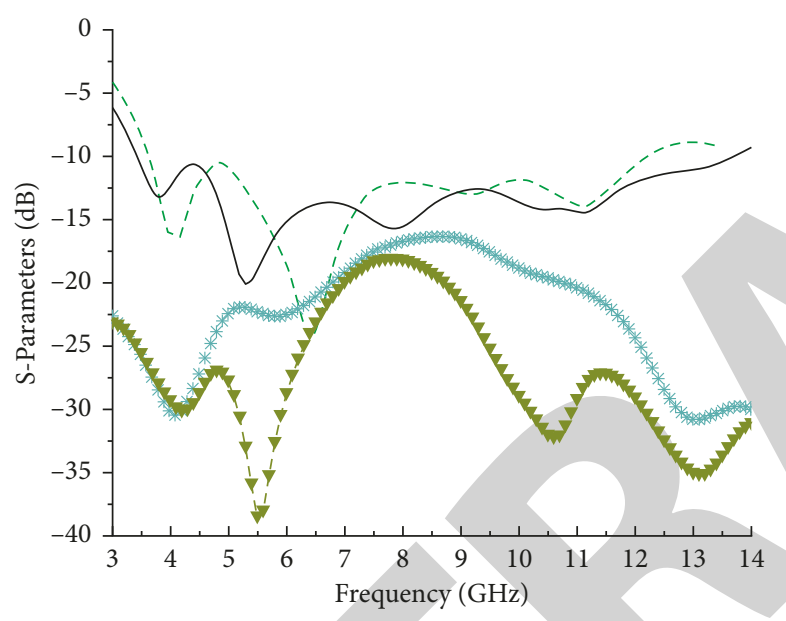

- - - $\mathrm{S}_{11}$ MIMO Antenna A - * - $\mathrm{S}_{12}$ MIMO Antenna A

- $S_{11}$ MIMO Antenna B - $-S_{12}$ MIMO Antenna B

(a)

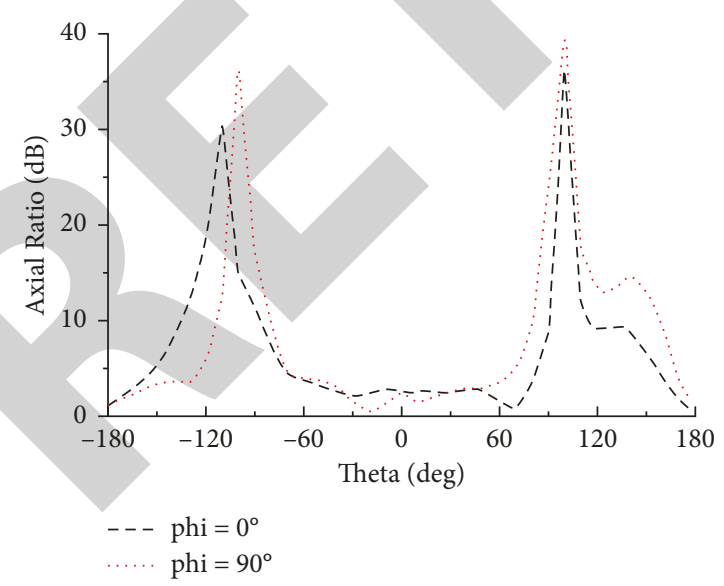

(c)

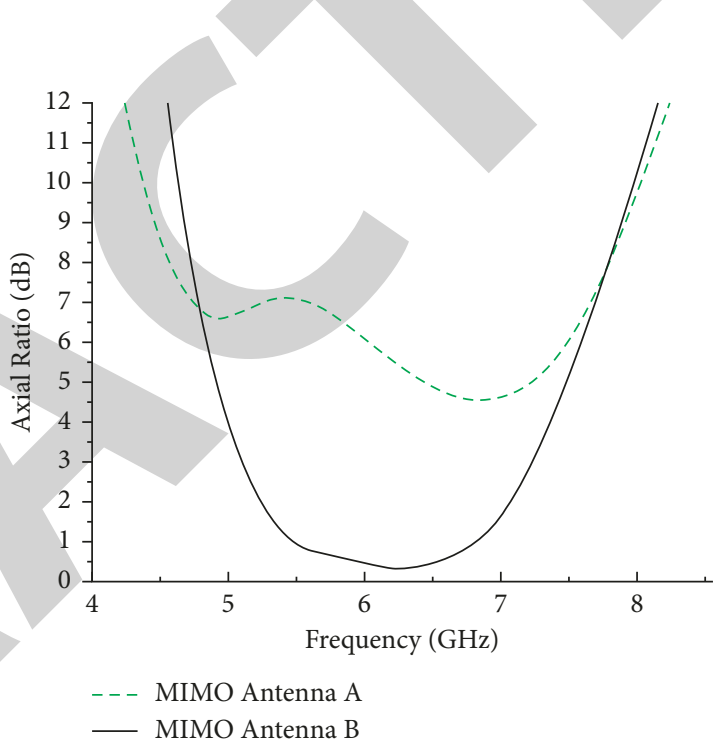

(b)

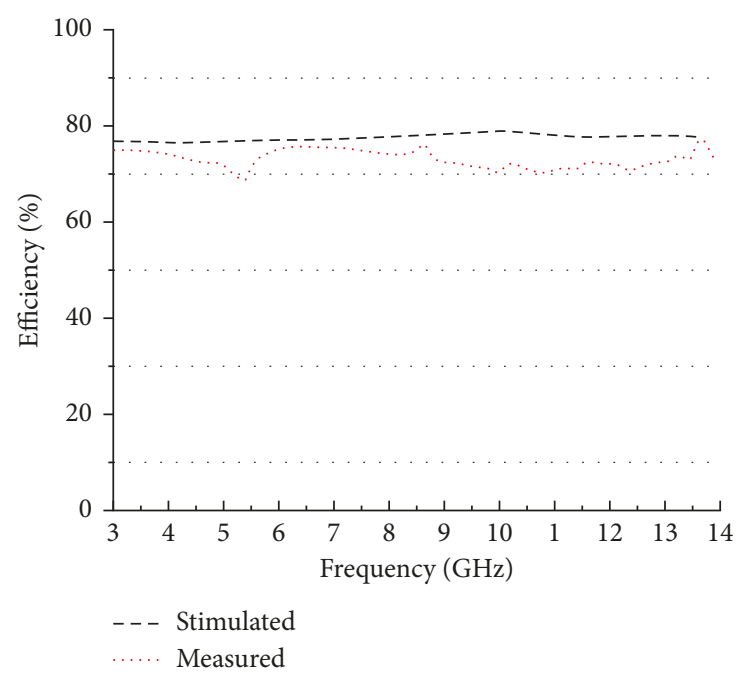

(d)

Figure 8: Simulated response of the stealth fabric textile MIMO antenna. (a) S-parameters, (b) axial ratio, (c) axial ratio beamwidth, and (d) antenna efficiency (left to right fig counting). 
TABLe 2: MIMO antenna-simulated results.

\begin{tabular}{llr}
\hline & ARBW & S11 \\
\hline Operating freq $(\mathrm{GHz})$ & $5.2-7.4$ & $3.4-13.6$ \\
Size $(\mathrm{mm} \times \mathrm{mm})$ & & $42 \times 32.5$ \\
Thickness of substrate & & $\operatorname{Tan}(\mathrm{d})=0.021 ; \operatorname{Er}=1.345$ \\
\hline
\end{tabular}

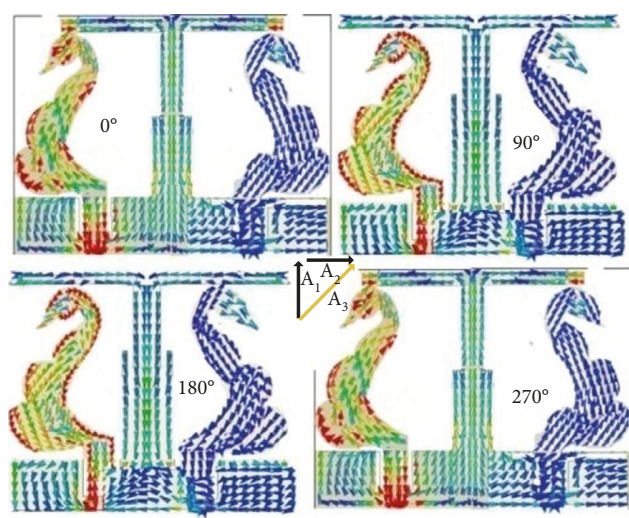

(a)

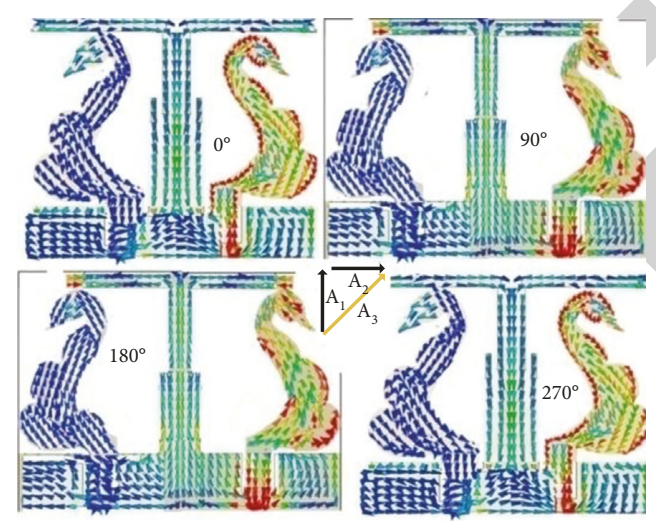

(b)

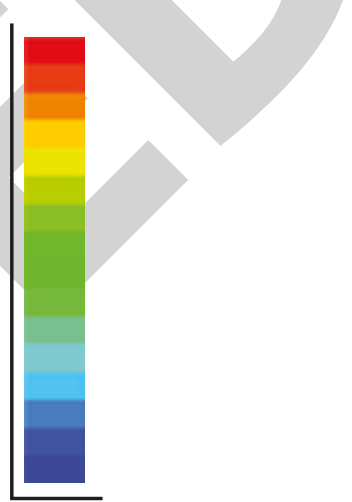

(c)

Figure 9: Surface current distribution at 5.25 GHz. (a) Port 1/LHCP and (b) port 2/RHCP. (c) Red indicates the highest peak power, and blue indicates the lowest peak radiation with arrow direction showing flow direction (left to right fig counting).

Figure 9(a) shows that the resultant (A3) has been inclined towards the upper right at $\mathrm{wt}=0^{\circ}$, while the vector addition (A3) has been inclined towards the lower right at $\mathrm{wt}=90^{\circ}$. In contrast, in Figure 9(b), the vector sum (A3) orients itself towards the upper left at wt $=0 *$, while the vector sum (A3) is oriented towards the lower left at wt $=90^{\circ}$. The load of $50 \mathrm{ohms}$ is supplied to port 2 when port 1 is excited, and vice versa. An animated representation of the surface current distribution of the proposed multiple-input multiple-output antenna at $8.50 \mathrm{GHz}$ can be seen in Figure 10. Despite the patch element in the center, the current distribution is homogeneous throughout the radiating patch area, validating the antenna gain.

2.1.6. Defected Ground Structures (DGS). The microwave circuit ground planes contain compact geometrical slots known as defected ground structures (DGS). As a result of defects on the ground plane, the distribution of current on the "ground plan" will be altered. This fluctuation will make most of the properties of a transmission line such as slot and line inductance, slot and line resistance, and slot and line capacitance. This phenomenon is experimentally verified by Khandelwal et al. [33]. Antennas, filters, coplanar waveguides, microwave amplifiers, and microwave assemblies have improved their performance by using DGS.

\section{Results and Discussion}

A vector network analyzer Anritsu MS2038C is used to measure the performance of the presented wearable multiple-input multiple-output antenna element. Figure 11(a) shows the textile MIMO antenna's measured and simulated reflection coefficients. Approximately $113 \%(3.6-13 \mathrm{GHz})$ and $121 \%(3.3-13.6 \mathrm{GHz})$ of the measured and simulated bandwidths exceed $10 \mathrm{~dB}$. According to Figure 11(a), the measured isolation between ports 1 and 2 is ground surpassing $17 \mathrm{~dB}$, whereas the simulated isolation is over $19 \mathrm{~dB}$. The decoupling structure is designed to operate between 4 and $6 \mathrm{GHz}$ to minimize coupling at lower frequencies.

In Figure 11(b), the axial ratios of the textile multipleinput multiple-output antenna are plotted (in the broadside direction). During the simulated waveform period for $5-7.3 \mathrm{GHz}$, the results are $37 \%(5-7.1 \mathrm{GHz})$ and $30 \%$ $(5-7.1 \mathrm{GHz})$. The axial ratio at $5.2 \mathrm{GHz}$ is $1.2 \mathrm{~dB}$ minimum (measured).

A plot of the calculated and computer-generated gain of the planned wearable antenna can be seen in Figure 11(c). At $8.5 \mathrm{GHz}$, the calculated peak gain is $5.70 \mathrm{~dB}$. Antenna measurements and simulations agree well. Because the textile materials and copper parts are joined by adhesive, there is a small difference.

3.1. Radiation Performance. The projected circularly polarised wearable multiple-input multiple-output antenna is illustrated with calculated and simulated radiation patterns for both $5.25 \mathrm{GHz}$ and $6.3 \mathrm{GHz}$ in Figure 12. Using a 50 -ohm load on port 2 and port 1, the MIMO antenna shows LHCP characteristics. MIMO antennas operate in the same manner as RHCP capabilities when port 2 is energized and port 1 is matched to a $50-\mathrm{ohm}$ load. Figures 12 (a)-12(d) depict the radiation patterns of the proposed double-sense $\mathrm{CP}$ wearable on garments multiple-input multiple-output antenna. Based on simulated and measured gains, Figure 11(c) shows excellent agreement between the two. A comparison of these graphs revealed how accurate HFSS software is with real-world antenna design. 

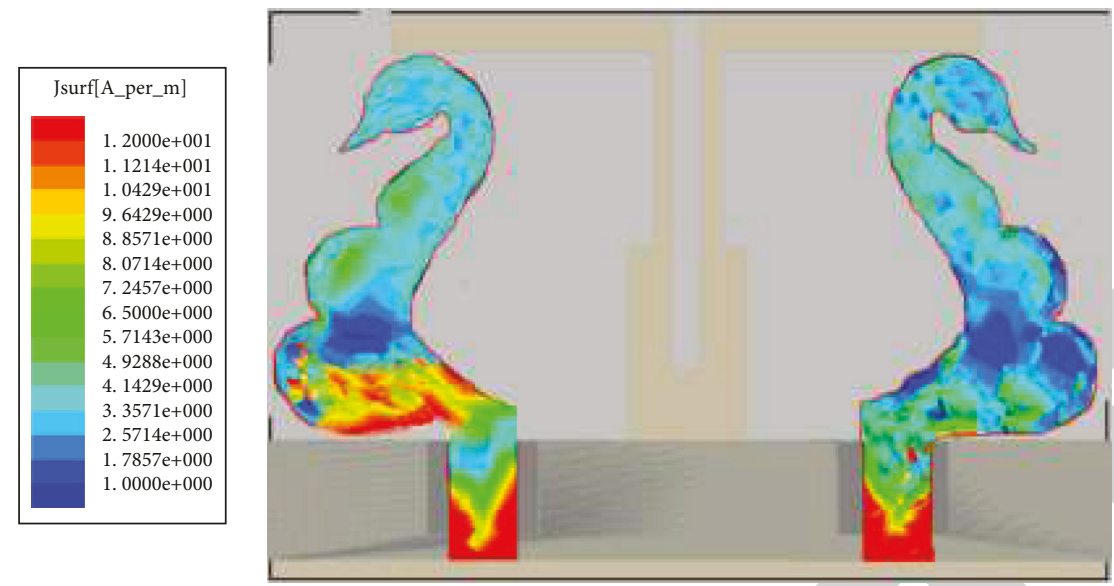

Figure 10: Simulated surface current distribution at $8.5 \mathrm{GHz}$.

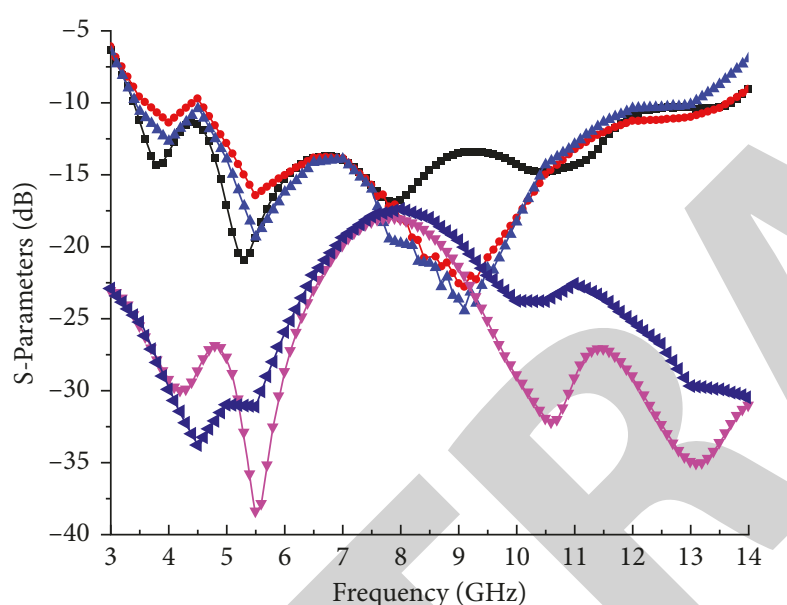

Frequency $(\mathrm{GHz})$

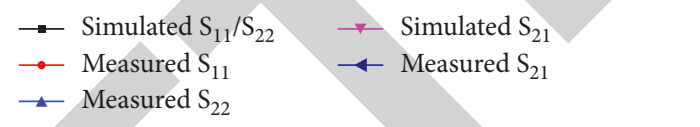

(a)

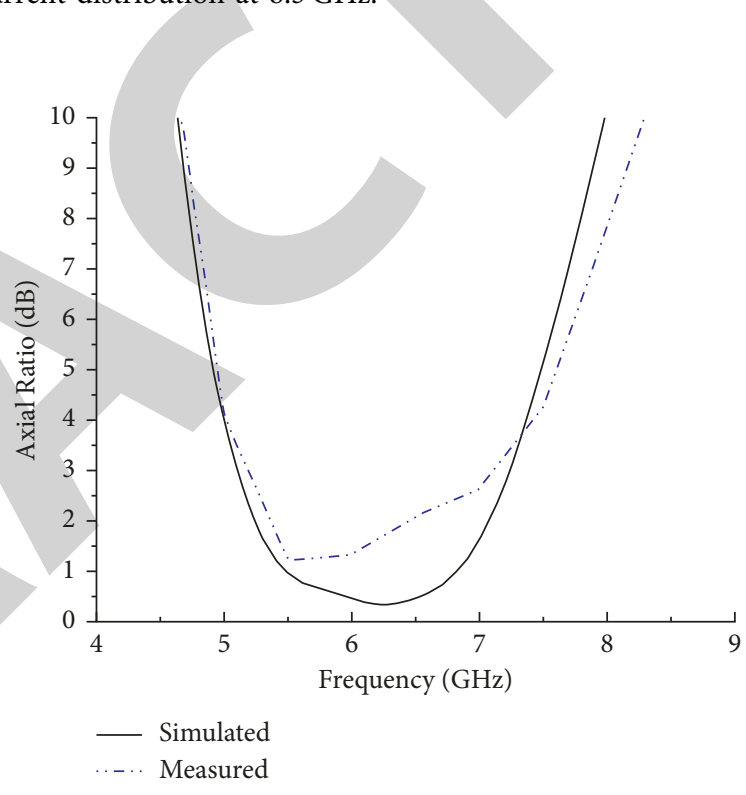

(b)

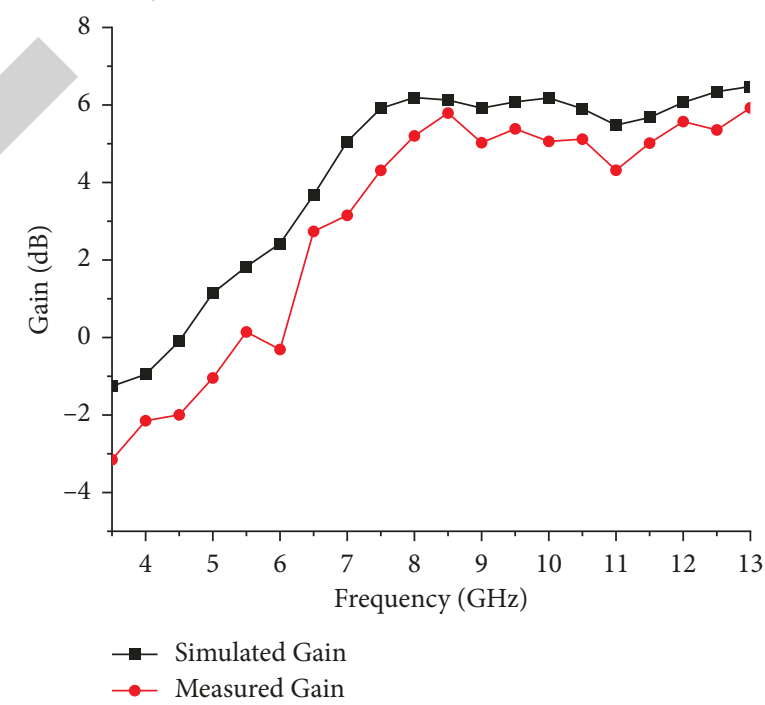

(c)

Figure 11: Simulated and measured response of the stealth fabric textile MIMO antenna. (a) S-parameters, (b) axial ratio, and (c) gain (left to right fig counting). 

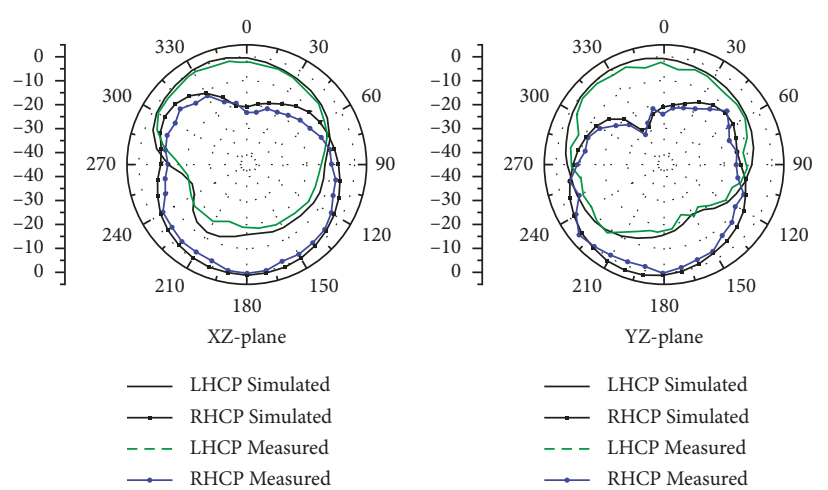

(a)

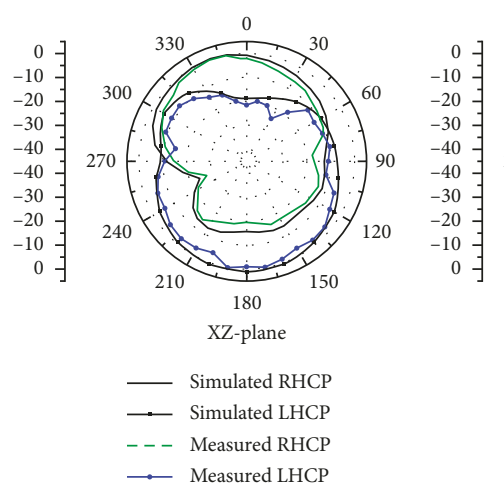

(c)

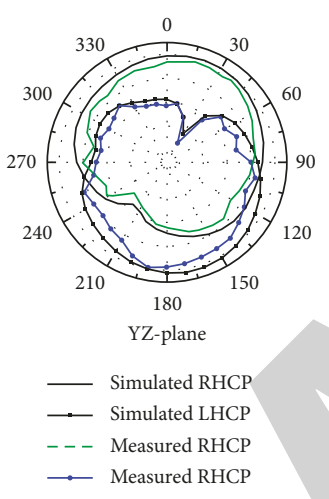

$\longrightarrow$ Measured RHCP
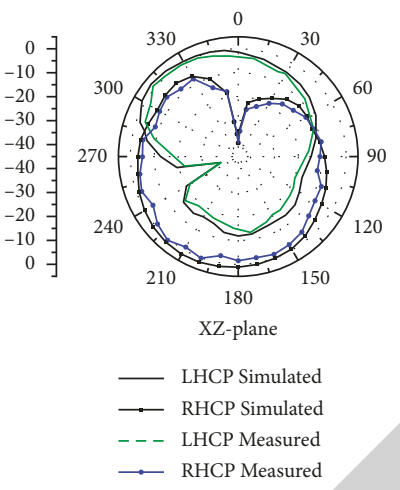

(b)

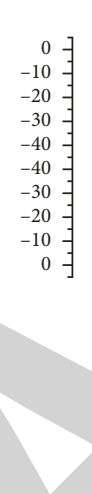

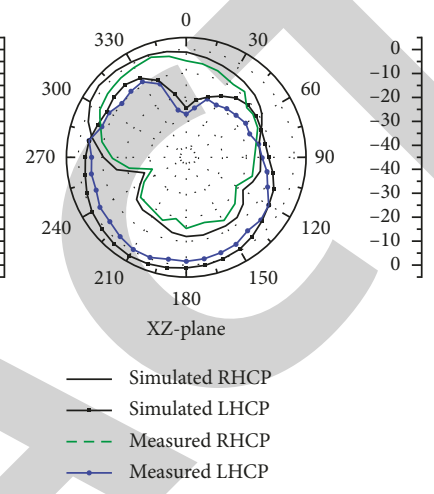
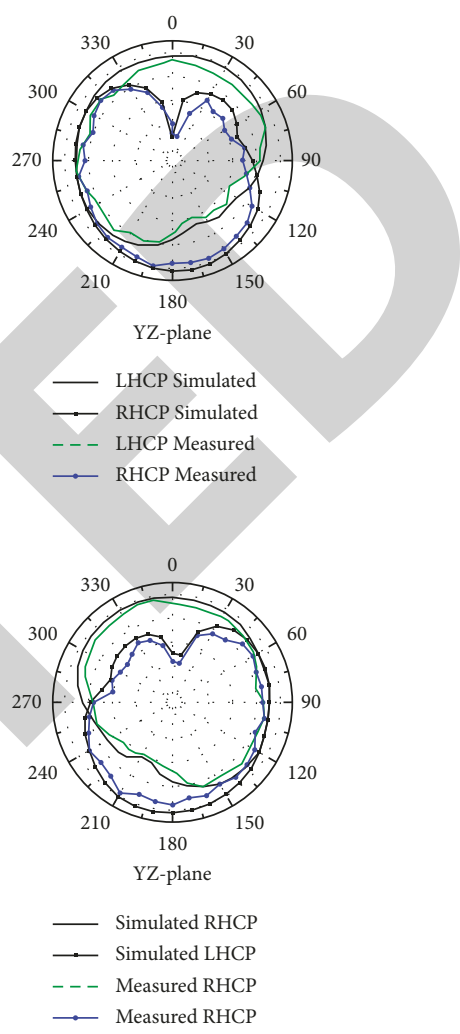

(d)

Figure 12: Measured and simulated radiation patterns of stealth fabric antenna. (a) $5.25 \mathrm{GHz} /$ port 1, (b) $6.3 \mathrm{GHz} /$ port 1, (c) $5.25 \mathrm{GHz} /$ port 2, and (d) $6.3 \mathrm{GHz} /$ port 2 .

3.2. MIMO Performance. As part of the evaluation of the behavior of the anticipated wearable antenna diversity system, multiple-input multiple-output parameters like envelope correlation coefficient (ECC), channel capacity loss $\mathrm{CCL}$ ), total active reflection coefficient (TARC), effective gain (MEG), diversity gain (DG), and mean are considered.

Envelope correlation coefficient (ECC) $<0.5$, diversity gain (DG) $>9.95$, TARC $<0 \mathrm{~dB}$, channel capacity loss (CCL) $<0.4 \mathrm{~b} / \mathrm{s} / \mathrm{Hz}$, and MEG ratio amid 0 and $-3 \mathrm{~dB}$ are necessary for efficient MIMO system functioning [34-37].

3.2.1. Diversity Gain (DG) and Envelope Correlation Coefficient (ECC). ECC helps develop correlations between antenna ports in MIMO systems. Evaluation of the envelope correlation coefficient (ECC) [37] can be achieved using the following relation:

$$
\mathrm{ECC}=\frac{\left|S_{11}^{*} S_{12}+S_{21}^{*} S_{22}\right|}{\left(1-\left|S_{11}\right|^{2}=\left|S_{21}\right|^{2}\right)\left(1-\left|S_{22}\right|^{2}-\left|S_{12}\right|^{2}\right)} .
$$

Figure 13(a) illustrates the simulated and measured envelope correlation coefficient (ECC) curves for the presented textile MIMO antenna. There is a difference in envelope correlation coefficient (ECC) among antenna elements 1 and 2 of fewer than 0.02 . The following relation may be used to calculate another important MIMO parameter:

$$
\mathrm{DG}=10 \sqrt{1-\mathrm{ECC}^{2}} .
$$

Figure 13(a) contains simulations and measurements of the proposed multiple-input multiple-output textile antenna. The diversity gain (DG) exceeds $9.96 \mathrm{~dB}$ in the case of the textile antenna.

3.2.2. TARC. Multiport antenna elements can interfere with each other's performances when they operate simultaneously. This effect is considered by TARC, which is stated as the square root of the ratio of the intensity of incident signals to the intensity of reflected signals. A total active reflective coefficient (TARC) may be calculated based on the following equation [38] for the proposed two-port MIMO antenna:

$$
\text { TARC }=\frac{\sqrt{\left(S_{11}+S_{22}\right)^{2}+\left(S_{21}+S_{12}\right)^{2}}}{\sqrt{2}} .
$$

The simulated and measured curves of the "total active reflective coefficient" (TARC) are shown in Figure 13(b). The measurement and simulation "total active reflective coefficient" (TARC) values here are a lesser amount than $-10 \mathrm{~dB}$ across the whole operating band.

3.2.3. Channel Capacity Loss (CCL) and MEG. Message transmission rates can be measured by evaluating the 


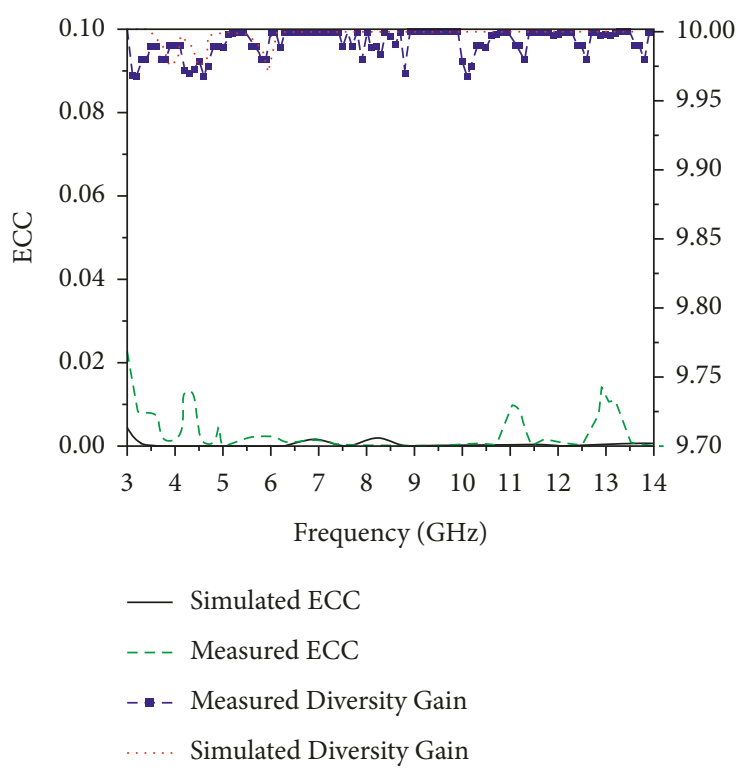

(a)

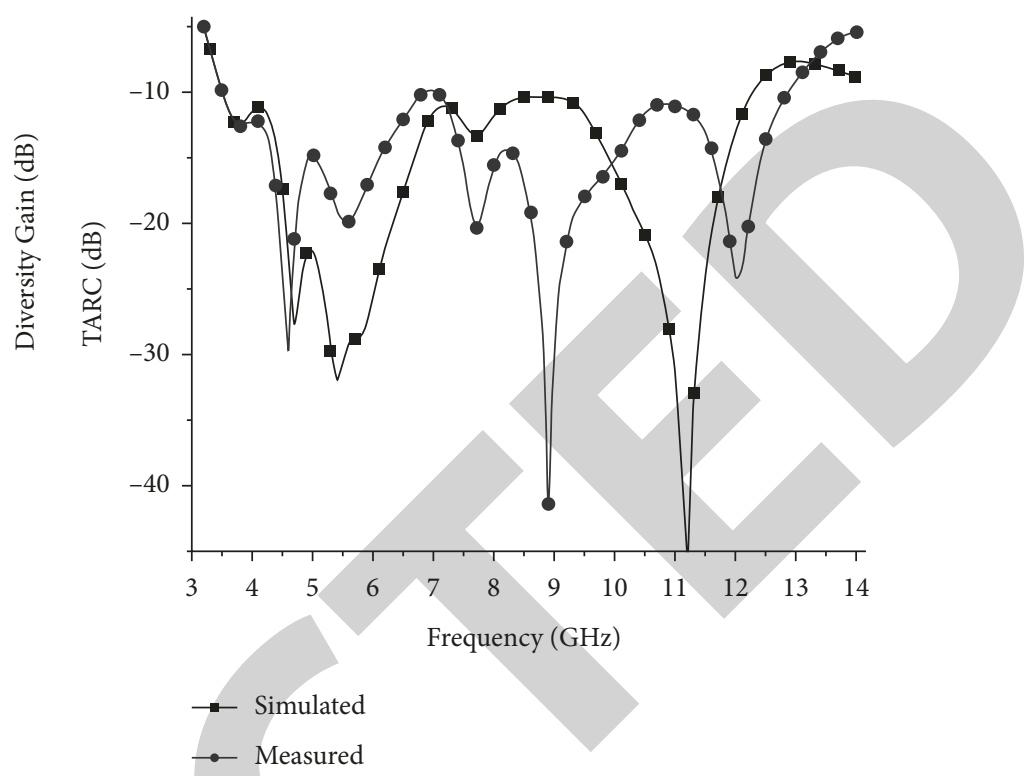

(b)

FIgURE 13: Diversity performance of the stealth fabric textile MIMO antenna. (a) ECC and DG and (b) TARC (left to right fig counting).

"channel capacity loss" (CCL) for a communication channel, and the "channel capacity loss" (CCL) can be calculated as [37]

$$
\begin{aligned}
C(\text { loss }) & =-\log _{2} \operatorname{det}\left(\beta^{R}\right) \\
, \quad \text { where } \beta^{R} & =\left[\begin{array}{ll}
R_{11} & R_{12} \\
R_{21} & R_{22}
\end{array}\right], R_{i i}=1-\left(\left|S_{11}\right|^{2}+\left|S_{22}\right|^{2}\right) \\
\text { and } R_{i j} & =-\left(S_{i i}^{*} S_{i j}+S_{i j}^{*} S_{j j}\right), \text { for } i, j=1 \text { or } 2 .
\end{aligned}
$$

In Figure 14(a), the proposed textile MIMO antenna's measured and simulated "channel capacity loss" (CCL) curves are shown. The "channel capacity loss" (CCL) values for the entire operating band are below $0.2 \mathrm{~b} / \mathrm{s} / \mathrm{Hz}$.

An MIMO antenna's gain is reflected by the MEG:

$$
\begin{aligned}
& \mathrm{MEG}_{1}=0.5 \eta_{1, \mathrm{rad}}=0.5\left[1-\left|S_{11}\right|^{2}-\left|S_{12}\right|^{2}\right], \\
& \mathrm{MEG}_{2}=0.5 \eta_{2, \mathrm{rad}}=0.5\left[1-\left|S_{12}\right|^{2}-\left|S_{22}\right|^{2}\right] .
\end{aligned}
$$

The study illustrates how the wireless environment impacts diversity. The MEG [34] can be calculated using the following equations.

3.2.4. Bending Effect Analysis. If worn in clothing on human body parts like the arms and thighs, the wearable antenna can bend. We ran simulations of the antenna at different radii to ensure its structural integrity, including $15 \mathrm{~mm}$, $25 \mathrm{~mm}, 35 \mathrm{~mm}$, and $45 \mathrm{~mm}$. Figures 15 and 16 illustrate the results from a simulated $S 11$ antenna and an axial ratio for various bending radii. To facilitate analyzing MIMO antennas, the bending of the antenna along the E-plane and along the $\mathrm{H}$-plane is analyzed. A simulation for the bending of the original antenna is compared with that of the simulated results presented in Figures 15(a) and 15(b). By comparing the results with the original results, it can be seen that the curves tend to lean to the larger frequency side by about $710 \mathrm{MHz}$.

The MIMO antenna performs well under bend conditions, exhibiting both an equal bandwidth and an excellent S11 result; however, the results deteriorate as the bend radius decreases because of an unbalanced impedance between the feed line and the port. Similar results are also observed in bending analyses in the $\mathrm{H}$-plane, where the resonating band shifts right as the bending radius decreases.

An antenna bending model simulating the axial ratio, shown in Figure 16, with a radius varying between $15 \mathrm{~mm}$ and $45 \mathrm{~mm}$, is illustrated. At $6 \mathrm{GHz}$, the $3 \mathrm{~dB} A R B W$ degrades because of the feed line offset, shifting to the lower side as the bending radius raises. S11 and the axial ratio of the proposed wearable antenna in the E-plane have been measured using Figures 17(a) and 17(b), with good agreement among the simulated and measured results.

Table 3 shows performance parameters for the MIMO antenna when bent in various bending situations, including total active reflective coefficient (TARC), diversity gain (DG), envelope correlation coefficient (ECC), MEG, and channel capacity loss (CCL). Because of changes in the current distribution on the ground plane of the antenna, the performance of the radiating antenna decreases as the bending radius increases.

Additionally, the antenna on the body is analyzed. A 4layer human arm shown in Figure 18(a) has intrinsic values of density, conductivity, loss tangent, and permittivity as shown in Table 4.

As can be seen in Figure 18(b), simulated S11 results for different bending radius are shifted somewhat towards the right due to the lossy nature of the human arm and the reduced length of the current path. 


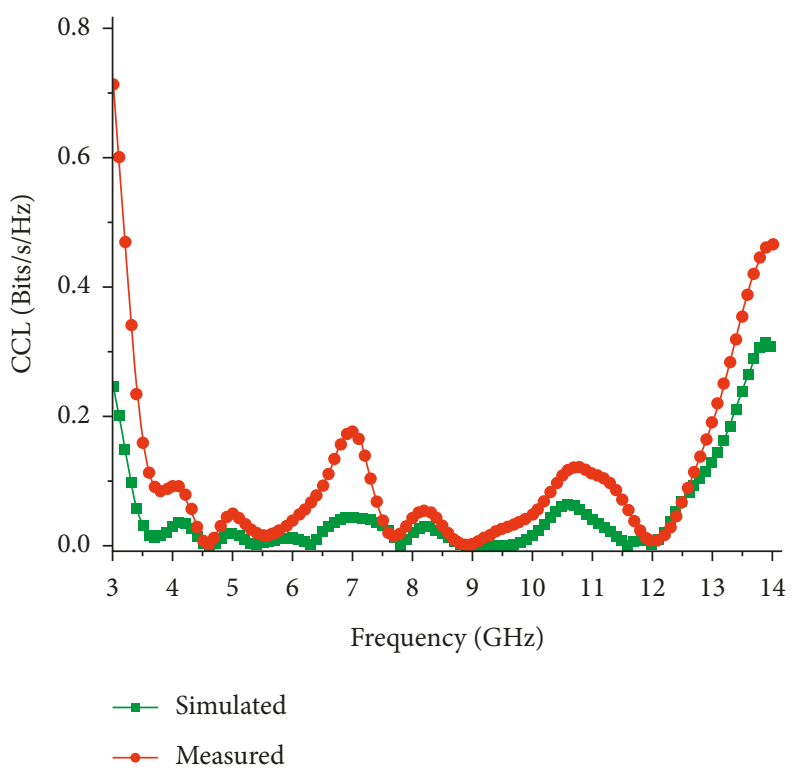

(a)

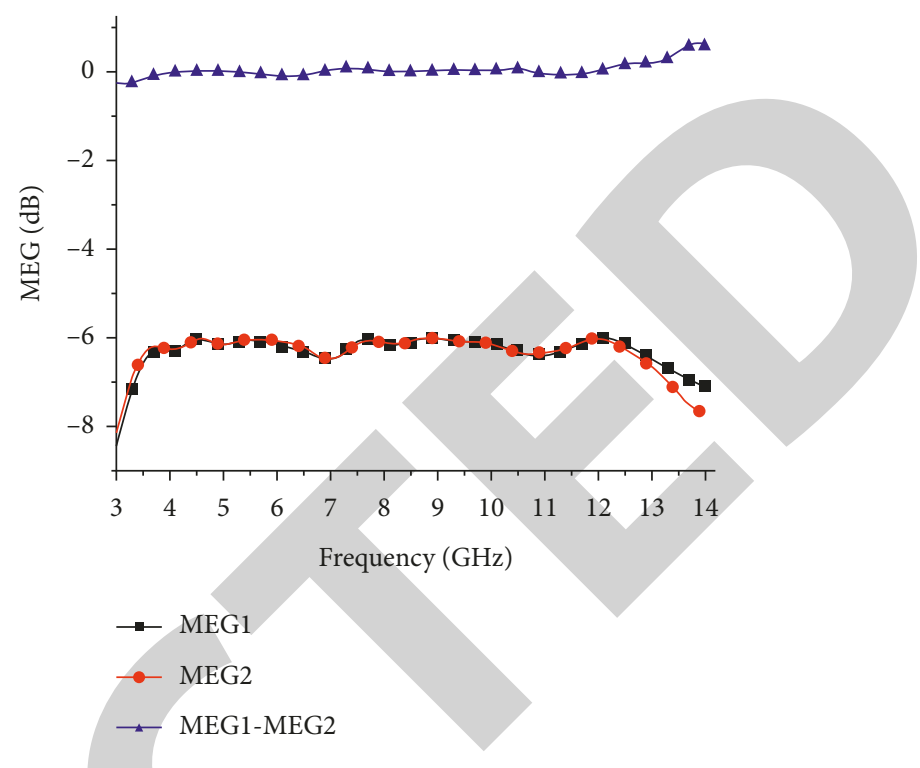

(b)

Figure 14: Proposed stealth fabric textile MIMO antenna. (a) Channel capacity loss (CCL) and (b) MEG (left to right fig counting).

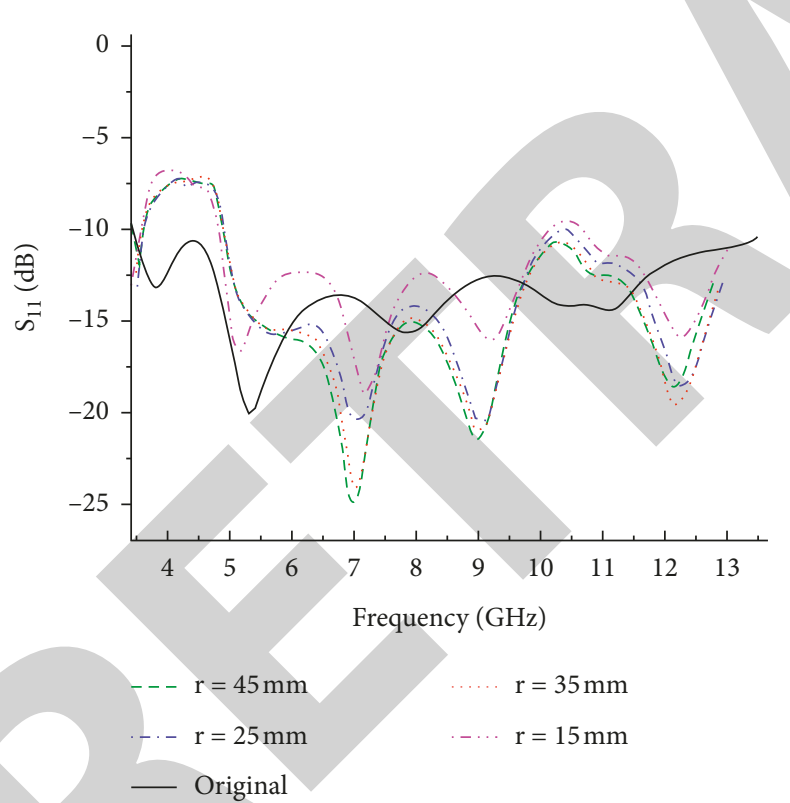

(a)

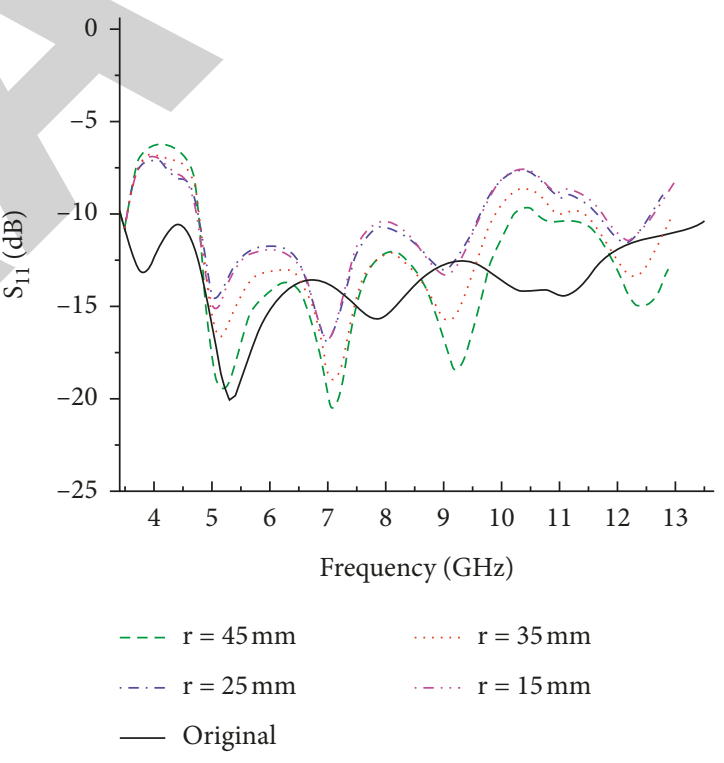

(b)

FIgURE 15: S11 comparison for different bending radii. (a) E-plane and (b) H-plane (left to right fig counting).

3.2.5. Specific Absorption Rate Characteristics. This relation [40] can be used to define the SAR (specific absorption rate):

$$
\operatorname{SAR}=\frac{d}{d t}\left(\frac{d E}{d m}\right)=\frac{d}{d t}\left(\frac{d E}{\rho \cdot d A}\right)\left(\frac{\mathrm{W}}{\mathrm{Kg}}\right)
$$

The incremental mass is $\mathrm{dm}$, the incremental energy is $d E$, and the volume element is $d A$. Based on a calculation of the antenna's maximum input power, $367.86 \mathrm{~mW}$ is the maximum power for $10 \mathrm{~g}$ of tissue at $2 \mathrm{~W}$ input powers, exceeding the greatest standard limit. Accordingly, the presented wearable antenna can operate inside its permissible boundaries.

An analysis of textile MIMO antennas and recently targeted textile wearable antennas is shown in Table 5. The parameters such as substrate material, antenna size, ARBW, operating bandwidth, sense of polarization, fractional bandwidth, gain, and isolation are compared. In [13-17], wearable antennas were presented as LPAs. Circular polarization is shown in [11], while [12,18-21] show dualsense CP antennas, but their operating bandwidth is small. Circular polarization is shown in [11], while $[12,18-21]$ 


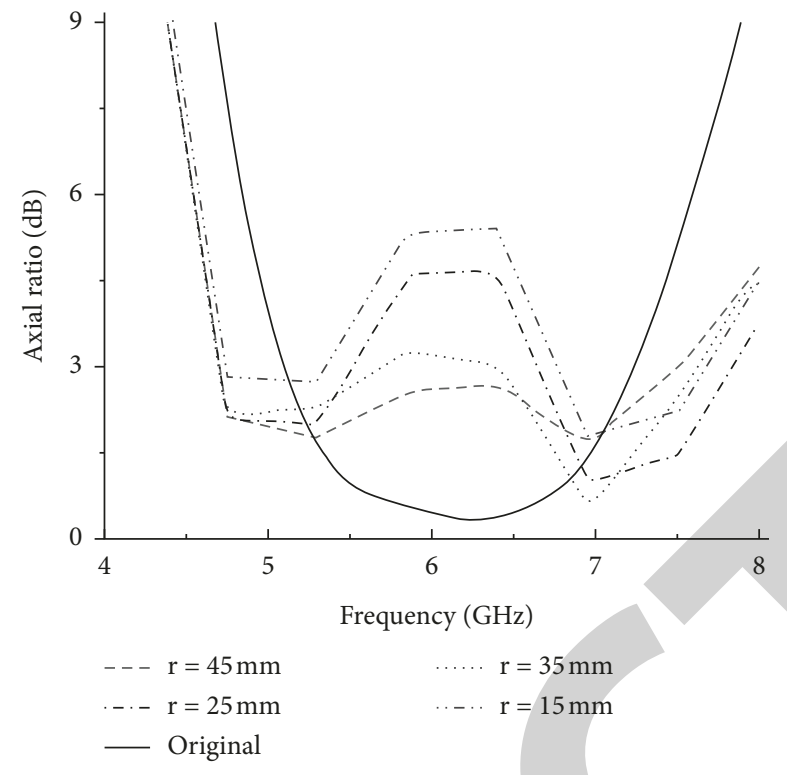

FIgURE 16: Axial ratio comparison for different bending radii in the E-plane.

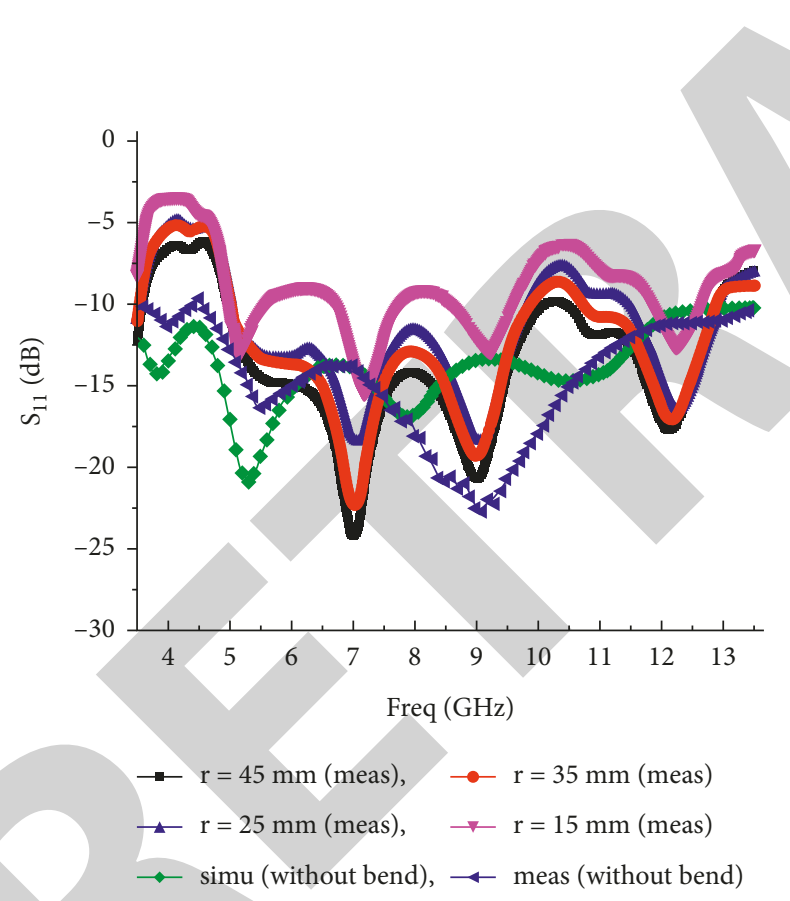

(a)

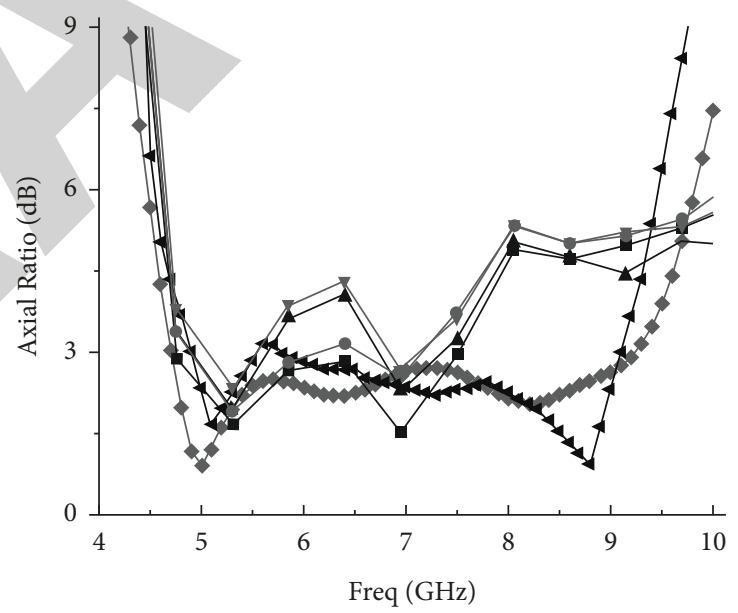

$\rightarrow \mathrm{r}=45 \mathrm{~mm}$ (meas), $\multimap \mathrm{meas}$ (without bend)
$\neg \mathrm{r}=25 \mathrm{~mm}$ (meas), $\rightarrow \mathrm{r}=35 \mathrm{~mm}$ (meas)
$\rightarrow \mathrm{simu}$ (without bend), $\rightarrow \mathrm{r}=15 \mathrm{~mm}$ (meas)

(b)

Figure 17: Performance comparison for different bending radii in the E-plane. (a) S11 and (b) axial ratio (left to right fig counting).

TABLE 3: MIMO antenna diversity performance for various bending radii.

\begin{tabular}{lccccc}
\hline \multirow{2}{*}{ Bending rad(mm) } & \multicolumn{3}{c}{ Parameter } \\
& ECC & DG $(\mathrm{dB})$ & MEG1-MEG2 $(\mathrm{dB})$ & TARC $(\mathrm{dB})$ & Channel capacity loss $(\mathrm{CCL})(\mathrm{b} / \mathrm{s} / \mathrm{Hz})$ \\
\hline 45 & 0.022 & 9.96 & \pm 0.5 & -10 & 0.2 \\
30 & 0.023 & 9.96 & $+/$ & -10 & 0.22 \\
20 & 0.024 & 9.94 & $+/$ & -9.5 & 0.23 \\
10 & 0.024 & 9.92 & $+/$ & -9.8 & 0.23 \\
\hline
\end{tabular}




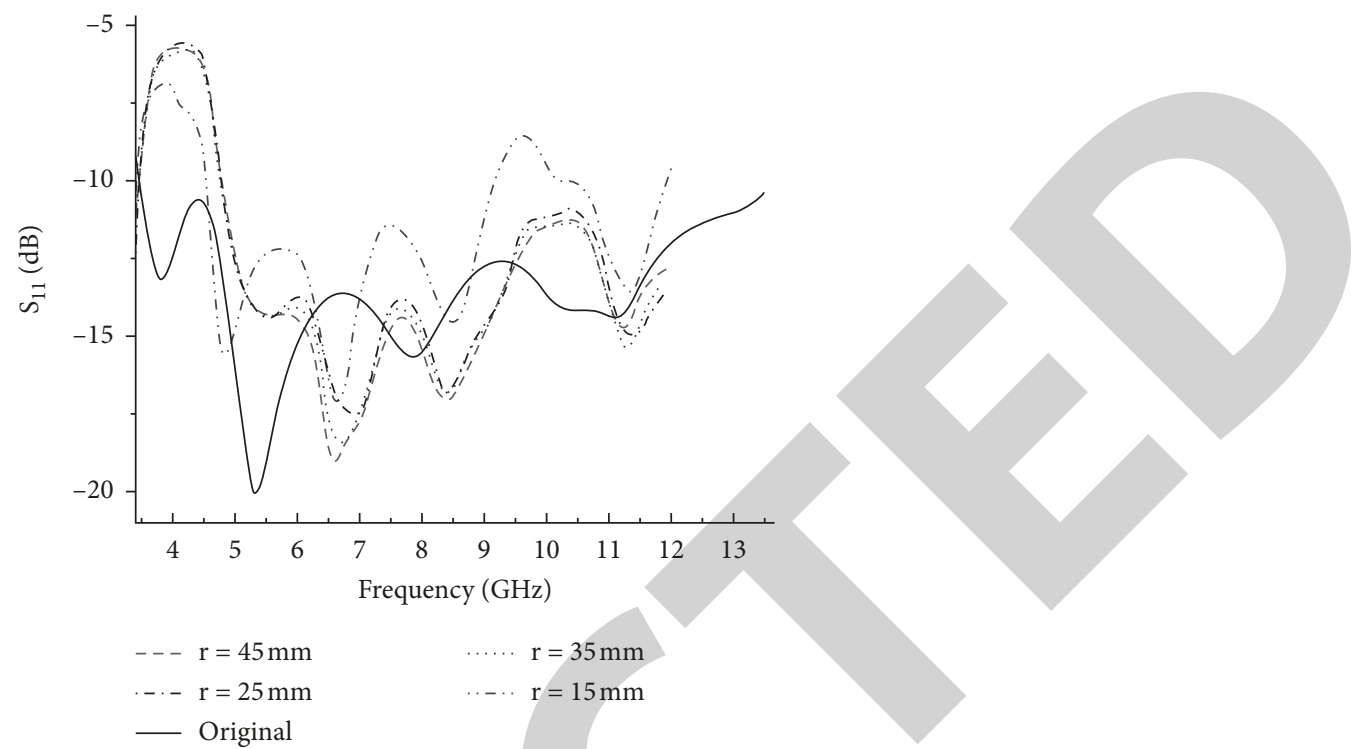

FIgURE 18: On-body performance of the antenna: S11 comparison for different bending radii in the E-plane.

TABLE 4: Intrinsic properties of human body tissues at $5.8 \mathrm{GHz}$ [39].

\begin{tabular}{lcccc}
\hline Property/tissue & Muscle & Bone & Fat & Skin \\
\hline Dielectric cont & 53.8 & 17.8 & 5.57 & 47.6 \\
Conductivity & 1.18 & 0.16 & 0.041 & 0.68 \\
Loss tangent & 0.24191 & 0.25244 & 0.19382 & 0.2835 \\
Density & 1040 & 1850 & 1000 & 1100 \\
Permittivity & 52.79 & 12.66 & 5.28 & 31.29 \\
\hline
\end{tabular}

TABLE 5: Correlation of the proposed stealth wearable on fabric antenna with the existing wearable antennas (MIMO).

\begin{tabular}{|c|c|c|c|c|c|c|c|c|}
\hline Reference & $\begin{array}{c}\text { Antenna size } \\
\left(\mathrm{mm}^{2}\right)\end{array}$ & $\begin{array}{l}\text { Gain } \\
(\mathrm{dB}) \\
\end{array}$ & $\begin{array}{c}\text { Operating BW } \\
(\mathrm{GHz})\end{array}$ & $\begin{array}{c}\text { Substrate } \\
\text { (Er) }\end{array}$ & $\begin{array}{c}\text { Fractional BW } \\
(\%)\end{array}$ & $\begin{array}{r}\text { ARBW } \\
(\mathrm{GHz}) \\
\end{array}$ & $\begin{array}{l}\text { Dual } \\
\text { sense }\end{array}$ & Isolation \\
\hline [11] & $40 * 40$ & 2.36 & $1.6-3.8$ & FR-4 (1.6) & 92.08 & $1.8-3.1$ & No & $>24$ \\
\hline [13] & $92.3 * 101.6$ & 5.8 & $\begin{array}{c}2.367-2.53 \\
5.14-5.86\end{array}$ & Textile (1.3) & $6.65-13.09$ & - & No & $>20$ \\
\hline [14] & $\operatorname{Pi}(21.1) 2$ & 4.2 & $2.4-2.49$ & FR-4 (1.6) & 3.68 & - & No & $>15$ \\
\hline$[15]$ & $38.1 * 38.1$ & 2.79 & $2.3-2.8$ & Textile (1.2) & 19.6 & - & No & $>12$ \\
\hline$[16]$ & $55 * 35$ & 6.9 & $2.64-12.28$ & Jeans (1.6) & 129.22 & - & No & $>26$ \\
\hline$[17]$ & $70 * 40$ & 4.4 & $2.4-8$ & Jeans (1.6) & 107.69 & - & No & $>22$ \\
\hline [12] & $60 * 60$ & 4 & $2.0-4.76$ & FR-4 (1.6) & 81.65 & $2.0-3.7$ & Yes & $>15$ \\
\hline [18] & $32 * 32$ & 3.8 & $1.4-8.73$ & FR-4 (1.6) & 144.71 & $3.74-8.8$ & Yes & $>20$ \\
\hline $\begin{array}{l}\text { Proposed } \\
\text { antenna }\end{array}$ & $42 * 34.5$ & 5.7 & $3.6-13$ & Textile (1.34) & 113.25 & $5.2-71$ & Yes & $>18$ \\
\hline
\end{tabular}

show dual-sense CP antennas, but their operating bandwidth is small. The proposed textile antenna has a smaller size and axial ratio than reported antennas and has a dualsense (LHCP/RHCP) design.

The proposed antenna parameters S11 for on-the-body antennas are illustrated in Figure 18. In the graph, $3.5 \mathrm{GHz}$ is the starting frequency, and $13 \mathrm{GHz}$ is the end frequency. A few oscillations are observed during the frequency range showing maximum S11 improvement at more than one frequency, which is an important manifestation of the proposed antenna.

\section{Conclusion}

A two-port stealth CP textile MIMO antenna for wideband $\mathrm{CP}$ is proposed in this paper. An overall size of $34.5 \times 42 \times 1 \mathrm{~mm}^{3}$ can be found on the textile antenna. ARBW and impedance bandwidth of $113 \%$ are observed in the proposed MIMO antenna. Diversity gain (DG) greater than the value $9.96 \mathrm{~dB}$, envelope correlation coefficient (ECC) less than the value 0.02 , and channel capacity loss (CCL) less than the value $0.2 \mathrm{~b} / \mathrm{s} / \mathrm{Hz}$ are displayed on the antenna. Without any additional decoupling elements, the 
isolation obtained exceeds $18 \mathrm{~dB}$. Human tissue models are also used to analyze the SAR of the proposed antenna, which is found to be within the acceptable range. This antenna is suitable for C-band uplink and downlink applications in wireless networks on and off the body, including WLAN, Bluetooth, and WiMAX.

\section{Data Availability}

All the data generated or analyzed during this study are included in this published article, which includes dimensions, processes, results, and conclusions.

\section{Conflicts of Interest}

The authors declare that they have no conflicts of interest.

\section{References}

[1] Y. S. Chen and T. Y. Ku, "A low-profile wearable antenna using a miniature high impedance surface for smartwatch applications," IEEE Antennas and Wireless Propagation Letters, vol. 15, pp. 1144-1147, 2016.

[2] R. Salvado, C. Loss, R. Gonçalves, and P. Pinho, "Textile materials for the design of wearable antennas: a survey," Sensors, vol. 12, no. 11, pp. 15841-15857, 2012.

[3] P. Nepa and H. Rogier, "Wearable antennas for off-body radio links at VHF and UHF bands: challenges, the state of the art, and future trends below $1 \mathrm{GHz}$," IEEE Antennas and Propagation Magazine, vol. 57, no. 5, pp. 30-52, 2015.

[4] B. Hu, G. P. Gao, L. L. He, X. D. Cong, and J. N. Zhao, "Bending and on-arm effects on a wearable antenna for $2.45 \mathrm{GHz}$ body area network," IEEE Antennas and Wireless Propagation Letters, vol. 15, pp. 378-381, 2016.

[5] K. N. Paracha, S. K. Abdul Rahim, P. J. Soh, and M. Khalily, "Wearable antennas: a review of materials, structures, and innovative features for autonomous communication and sensing," IEEE Access, vol. 7, pp. 56694-56712, 2019.

[6] M. Klemm, I. Locher, and G. Tröster, "A novel circularly polarized textile antenna for wearable applications," in Proceedings of the 7th European Conference Wireless Technology, pp. 137-140, Tokyo, Japan, October 2004.

[7] Z. H. Jiang, Z. Cui, T. Yue, Y. Zhu, and D. H. Werner, "Compact, highly efficient, and fully flexible circularly polarized antenna enabled by silver nanowires for wireless bodyarea networks," IEEE Transactions on Biomedical Circuits and Systems, vol. 11, no. 4, pp. 920-932, 2017.

[8] Z. H. Jiang and D. H. Werner, "A compact, wideband circularly polarized co-designed filtering antenna and its application for wearable devices with low SAR," IEEE Transactions on Antennas and Propagation, vol. 63, no. 9, pp. 3808-3818, 2015.

[9] F. A. Dicandia, S. Genovesi, and A. Monorchio, "Analysis of the performance enhancement of MIMO systems employing circular polarization," IEEE Transactions on Antennas and Propagation, vol. 65, no. 9, pp. 4824-4835, 2017.

[10] H. Li, J. Xiong, Z. Ying, and S. L. He, "Compact and low profile co-located MIMO antenna structure with polarisation diversity and high port isolation," Electronics Letters, vol. 46, no. 2, pp. 108-110, 2010.

[11] A. Iqbal, A. Smida, A. J. Alazemi, M. I. Waly, N. Khaddaj Mallat, and S. Kim, "Wideband circularly polarized MIMO antenna for high data wearable biotelemetric devices," IEEE Access, vol. 8, pp. 17935-17944, 2020.

[12] R. K. Saini and S. Dwari, "A broadband dual circularly polarized square slot antenna," IEEE Transactions on Antennas and Propagation, vol. 64, no. 1, pp. 290-294, 2016.

[13] S. Yan, P. J. Soh, and G. A. E. Vandenbosch, "Dual-band textile MIMO antenna based on substrate-integrated waveguide (SIW) technology," IEEE Transactions on Antennas and Propagation, vol. 63, no. 11, pp. 4640-4647, 2015.

[14] D. Wen, Y. Hao, M. O. Munoz, H. Wang, and H. Zhou, "A compact and low-profile MIMO antenna using a miniature circular high-impedance surface for wearable applications," IEEE Transactions on Antennas and Propagation, vol. 66, no. 1, pp. 96-104, 2018.

[15] H. Li, S. Sun, B. Wang, and F. Wu, "Design of compact singlelayer textile MIMO antenna for wearable applications," IEEE Transactions on Antennas and Propagation, vol. 66, no. 6, pp. 3136-3141, 2018.

[16] A. K. Biswas and U. Chakraborty, "Compact wearable MIMO antenna with improved port isolation for ultra-wideband applications," IET Microwaves, Antennas Propagation, vol. 13, no. 4, pp. 498-504, 2019.

[17] A. K. Biswas and U. Chakraborty, "A compact wide band textile MIMO antenna with very low mutual coupling for wearable applications," International Journal of RF and Microwave Computer-Aided Engineering, vol. 29, no. 8, Article ID e21769, 2019.

[18] D. S. Chandu and S. S. Karthikeyan, "A novel broadband dual circu- larly polarized microstrip-fed monopole antenna," IEEE Transactions on Antennas Propagation, vol. 65, no. 3, pp. 1410-1415, 2017.

[19] M. Y. Jamal, M. Li, and K. L. Yeung, "Isolation enhancement of closely packed dual circularly polarized MIMO antenna using hybrid technique," IEEE Access, vol. 8, pp. 11241-11247, 2020.

[20] U. Ullah, I. B. Mabrouk, and S. Koziel, "Enhanced-performance circularly polarized MIMO antenna with polarization/ pattern diversity," IEEE Access, vol. 8, pp. 11887-11895, 2020.

[21] L. Qu, H. Piao, Y. Qu, H. H. Kim, and H. Kim, "Circularly polarised MIMO ground radiation antennas for wearable devices," Electronics Letters, vol. 54, no. 4, pp. 189-190, 2018.

[22] M. U. Afzal, A. Lalbakhsh, and K. P. Esselle, "A low-profile beam-tilted antenna array for receiving direct-broadcast satellite services," in Proceedings of the 2018 IEEE 7th AsiaPacific Conference on Antennas and Propagation (APCAP), pp. 147-148, Institute of Electrical and Electronics Engineers (IEEE), Auckland, New Zealand, August 2018.

[23] M. Alibakhshikenari, B. S. Virdee, P. Shukla et al., "Metasurface wall suppression of mutual coupling between microstrip patch antenna arrays for THz-band applications," Progress In Electromagnetics Research Letters, vol. 75, pp. 105-111, 2018.

[24] M. Alibakhshikenari, B. S. Virdee, C. H. See et al., "Study on isolation improvement between closely-packed patch antenna arrays based on fractal metamaterial electromagnetic bandgap structures," IET Microvave Antennas \& Propagation, vol. 12, no. 14, pp. 2241-2247, 2018.

[25] M. Alibakhshikenari, B. S. Virdee, P. Shukla et al., "Antenna mutual coupling suppression over wideband using embedded periphery slot for antenna arrays," Electronics, vol. 7, no. 9, p. 198, 2018.

[26] B. Mohamadzade, A. Lalbakhsh, R. B. V. B. Simorangkir, A. Rezaee, R. M. Hashmi, and R. M. Hashmi, "Mutual coupling reduction in microstrip array antenna by employing 
cut side patches and EBG structures," Progress In Electromagnetics Research M, vol. 89, pp. 179-187, 2020.

[27] M. Alibakhshikenari, B. S. Virdee, P. Shukla et al., "Interaction between closely packed array antenna elements using metasurface for applications such as MIMO systems and synthetic aperture radars," Radio Science, vol. 53, no. 11, pp. 1368-1381, 2018.

[28] P. R. Gooran, L. Ali, H. Moradi, and M. Jamshidi, "Compact and wideband printed log-periodic dipole array antenna using multi-sigma and multi-tau techniques," Journal of Electromagnetic Waves and Applications, vol. 33, no. 6, pp. 697-706, 2019.

[29] M. Alibakhshikenari, F. Babaeian, B. S. Virdee et al., "A comprehensive survey on "various decoupling mechanisms with focus on metamaterial and metasurface principles applicable to sar and mimo antenna systems"," IEEE Access, vol. 8, pp. 192965-193004, 2020.

[30] P. Laxman and A. Jain, "Circularly polarized (CP) wideband on fabric (Textile) stealth MIMO antenna for wearable wireless UWB applications," Wireless Personal Communications, vol. 10, 2021.

[31] S. Kumar, D. Nandan, K. Srivastava et al., "Wideband circularly polarized textile MIMO antenna for wearable applications," IEEE Access, vol. 9, pp. 108601-108613, 2021.

[32] Y. Al-Naiemy, T. A. Elwi, H. R. Khaleel, and H. Al-Rizzo, “A systematic approach for the design, fabrication, and testing of microstrip antennas using inkjet printing technology," International Scholarly Research Notices, vol. 2012, Article ID 132465, 11 pages, 2012.

[33] M. K. Khandelwal, B. K. Kumar, and S. Kumar, "Defected ground structure: fundamentals, analysis, and applications in modern wireless trends," International Journal of Antennas and Propagation, vol. 2017, Article ID 2018527, 22 pages, 2017.

[34] J. Nasir, M. H. Jamaluddin, M. Khalily, M. R. Kamarudin, I. Ullah, and R. Selvaraju, "A reduced size dual port MIMO DRA with high isolation for $4 \mathrm{G}$ applications," International Journal of RF and Microwave Computer-Aided Engineering, vol. 25, no. 6, pp. 495-501, 2015.

[35] S. H. Chae, S. K. Oh, and S. O. Park, "Analysis of mutual coupling, correlations, and TARC in wibro MIMO array antenna," IEEE Antennas and Wireless Propagation Letters, vol. 6, pp. 122-125, 2007.

[36] H. S. Singh, G. K. Pandey, P. K. Bharti, and M. K. Meshram, "Design and performance investigation of a low profile MIMO/diversity antenna for WLAN/WiMAX/HIPERLAN applications with high isolation," International Journal of $R F$ and Microwave Computer-Aided Engineering, vol. 25, no. 6, pp. 510-521, 2015.

[37] Y. K. Choukiker, S. K. Sharma, and S. K. Behera, "Hybrid fractal shape planar monopole antenna covering multiband wireless communications with MIMO implementation for handheld mobile devices," IEEE Transaction Antennas Propagation, vol. 62, no. 3, pp. 1483-1488, 2014.

[38] S. I. Jafri, R. Saleem, M. F. Shafique, and A. K. Brown, "Compact reconfigurable multiple-input-multiple-output antenna for ultra wideband applications," IET Microwave, Antennas Propagation, vol. 10, no. 4, pp. 413-419, 2016.

[39] U. Ali, S. Ullah, J. Khan et al., "Design and SAR analysis of wearable antenna on various parts of human body, using conventional and artificial ground planes," Journal of
Electrical Engineering and Technology, vol. 12, no. 1, pp. 317-328, 2017.

[40] Sponsor Committee SASB/SCC39 - SCC39 - International Committee on Electromagnetic Safety Society IEEE-SASB Coordinating Committees, IEEE Recommended Practice for Measurements and Computations of Radio Frequency Electromagnetic Fields With Respect to Human Exposure to Such Fields, $100 \mathrm{kHz}$ to $300 \mathrm{GHz}$, IEEE Standard C95.3-2002, 2002. 